
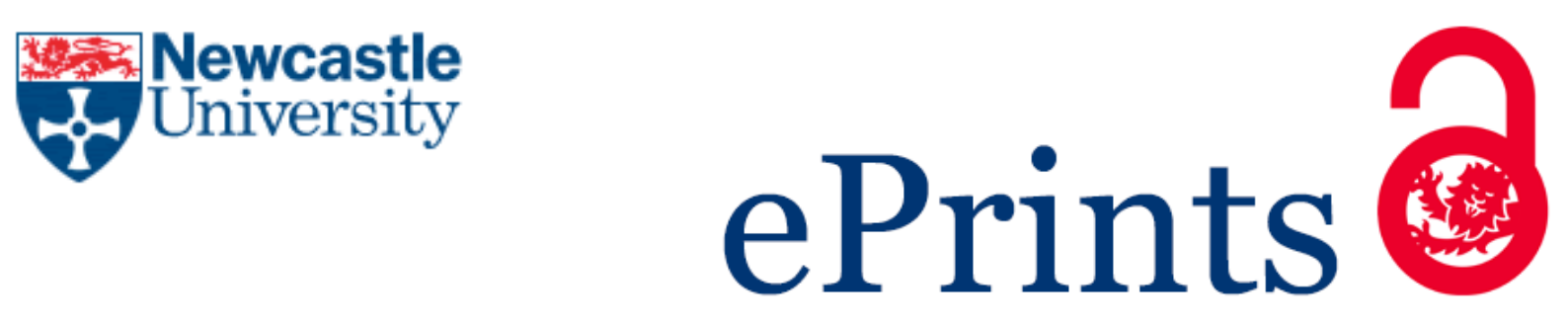

Nulty P, Theocharis Y, Popa SA, Parnet O, Benoit K.

Social media and political communication in the 2014 elections to the

European Parliament.

Electoral studies 2016, 44, 429-444.

\title{
Copyright:
}

(C) 2016. This manuscript version is made available under the CC-BY-NC-ND 4.0 license

DOI link to article:

https://doi.org/10.1016/i.electstud.2016.04.014

Date deposited:

$01 / 12 / 2017$

Embargo release date:

19 November 2017

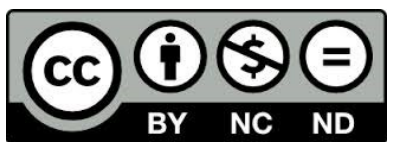

This work is licensed under a

Creative Commons Attribution-NonCommercial-NoDerivatives 4.0 International licence 


\title{
Social Media and Political Communication in the 2014 Elections to the European Parliament*
}

\author{
Paul Nulty ${ }^{1}$, Yannis Theocharis ${ }^{2}$, Sebastian Adrian Popa ${ }^{2}$, Olivier Parnet ${ }^{3}$, \\ and Kenneth Benoit ${ }^{1}$ \\ ${ }^{1}$ London School of Economics and Political Science \\ ${ }^{2}$ Mannheim Centre for European Social Research (MZES) \\ ${ }^{3}$ TNS Europe
}

May 6, 2016

\begin{abstract}
Social media play an increasingly important part in the communication strategies of political campaigns by reflecting information about the policy preferences and opinions of political actors and their public followers. In addition, the content of the messages provides rich information about the political issues and the framing of those issues during elections, such as whether contested issues concern Europe or rather extend pre-existing national debates. In this study, we survey the European landscape of social media using tweets originating from and referring to political actors during the 2014 European Parliament election campaign. We describe the language and national distribution of the messages, the relative volume of different types of communications, and the factors that determine the adoption and use of social media by the candidates. We also analyze the dynamics of the volume and content of the communications over the duration of the campaign with reference to both the EU integration dimension of the debate and the prominence of the most visible list-leading candidates. Our findings indicate that the lead candidates and their televised debate had a prominent influence on the volume and content of communications, and that the content and emotional tone of communications more reflects preferences along the EU dimension of political contestation rather than classic national issues relating to left-right differences.
\end{abstract}

*Supported by the "European Election Study 2014" MZES project, and by European Research Council grant ERC-2011-StG 283794-QUANTESS. 
The complexity of communicating political messages by European parties and national parties distributed across the 28 member states of the EU poses a significant challenge. Consequently, most communication occurs within national and linguistic boundaries. Modern social media, however, provides a unique technological means to bridge linguistic divides, as well as to extend the reach of political communications by candidates and parties to the electorates located in the multi-national political system of the European Union. Despite this potential, very little is yet known about the role or effects of social media in European political campaigns. Our study addresses this gap by providing a systematic exploration of the social media space in Europe-wide politics, by examining election-related content on Twitter, the micro-blogging platform with more than 316 million active users worldwide. In 2014, some 18\% of MEP candidates had Twitter accounts, but relatively little is known about why only one in five candidates used this medium, what are the patterns of their usage, or what patterns can be found in the content of their messages. With respect to EU citizens, we know even less about how they use Twitter to communicate to or about European election parties or candidates.

In this paper we map the usage of social media in the 2014 European Parliament (EP) election focusing on Twitter, including an analysis of the networks of followers, the usage of national and cross-national hashtags related to the EU, and the types of Twitter communication. We focus on Twitter because it is the most widely adopted platform by politicians for the purposes of personal promotion, diffusing policy positions, mobilization and because it enables a more direct and interactive engagement with the public. Applying sentiment analysis to the text of the Tweets, we also assess various levels of sentiment associated with particular concepts or individuals or countries. Finally, by looking at the associations of message content with external policy measures of candidate parties, we are able to map content and associations within the text to get a picture of the dialogue across the European issue space of electoral competition. Our approach allows us not only to observe communication patterns from a structural point of view, but also to investigate the themes communicated in a period during which political communication is heightened, and to do so in a multi-national, multi-language context. 
In what follows we first survey existing research on social media and electoral campaigning in Europe and subsequently discuss the European dimension of political contestation which provides the theoretical background from which we derive our expectations for this exploratory study. After discussing our data collection process and methodology, we describe tweets and how, present results obtained by social network analysis, sentiment analysis, and word associations, and offer some concluding remarks along with suggestions for further research.

\section{Social Media and Political Communication}

\subsection{Social media use in electoral campaigns}

Election campaigns fundamentally rely on communication. Over the last decade, changes in the communication environment due to innovations in digital technologies (Chadwick, 2014; Castells, 2009), which themselves accompanied a process of modernisation and professionalisation of electoral competition (Lees-Marshment, 2001), have forced political elites to adopt and integrate in their campaigns increasingly sophisticated digital communication practices. Faced with a sharp decline in party membership and a more demanding, assertive and distrustful public increasingly willing to intervene directly in the political process (Dalton and Welzel, 2014) (often through the use of digital media-enabled personalised forms of participation), political parties and candidates embraced new online tools as part of their campaign communication (Gibson, 2013) Social networking sites like Facebook, microblogs like Twitter and video-sharing sites like YouTube have not only given politicians a powerful avenue for interacting with a more demanding citizenry, but also have allowed them to offer more personalised images to the public and have given less resourceful parties the opportunity to match well-funded campaigns in sophistication, using creative and relatively inexpensive strategies. Candidates, members of parliament, and local committee members worldwide are now providing information about their policy positions, invite followers to campaign events or meetings on Facebook, and interact with their constituencies "on the go" and through short messages on Twitter rather than long and time-consuming 
posts on their blogs or websites (Vergeer et al., 2011; Bode and Dalrymple, 2014).

Research has extensively documented the integration of new media tools, and Twitter specifically, in election campaigns held in numerous European countries (see Strandberg, 2013; Gibson, 2013; Jungherr, 2014a), yet it has yet to acheive the central role that social media has played in recent US elections. Developments such as what Gibson has termed "citizen-initiated"-campaigning, aiming to denote the devolving power over core tasks to the grassroots, is only now slowly emerging in Europe (Gibson, 2013), though with significant variation across countries and parties (Hansen and Kosiara-Pederson, 2014; Jungherr, 2014a). Despite lacking in innovation, however, European candidates do use digital media for other purposes. Facebook and Twitter have allowed candidates to increase their exposure at very little cost (as well as significant risk (Theocharis et al., 2015)), a development that enabled lesser known candidates to rise from obscurity (Vergeer et al., 2011). Social media has also provided a platform for citizens to communicate directly with political candidates.

\subsection{Social media campaigning in European elections}

Research into the integration of social media in European election campaigns is underdeveloped, due in large part to the phenomenon itself being limited. Even by comparison with their national political counterparts, European election candidates have been slower to adopt on-line campaigning tools. For example, Vergeer, Hermans and Cuhna (Vergeer et al., 2012), in their comparative study of European parties' and candidates' use of websites (and therefore of a much less interactive platform than social media) during the 2009 EP elections found significant interactivity divides with many candidates being only minimally active on them. Their study's insights corroborate findings by Lilleker et al. (2011) showing that, despite the integration of some more interactive Web 2.0 features into the 2009 European campaign websites, these were used far more for static advertising than for interactive communication. Lilleker et al. (2011) also found that the integration of "Web 2.0" features on campaign websites by extreme left- and right-wing parties - a topic for which we continue to know very little, especially with regard to interactive social media 
- was associated with policy extremism. Right-wing parties offered the greatest opportunities for interaction, while far left parties were at the frontier of information provision (Lilleker et al., 2011, 206). In the same vein, an overview of the literature on Twitter use by candidates by Jungherr (2014b) confirms that past research has shown that politicians that lie on extreme positions in the ideological continuum use Twitter more frequently and intensively than moderates.

More recent studies have focused exclusively on social media, rather than the integration of Web 2.0 features on older platforms such as web sites. In a first look at the use of social media during the 2014 EP elections, Lorenzo-Rodríguez and Madariaga (2015) found that candidates' presence on social media is strongly related to incumbency status, party visibility, position on the ballot, as well as Internet penetration in a given country. Usage of these platforms seems specifically designed for campaning, rather than general political communication: once elections are over, there is very little use of Twitter by parliamentarians for the purpose of campaigning outside electoral periods Larsson (2015). To date, no studies have examined the content of social media communications by European candidates.

With the greatest integration of social media tools in an EP campaign thus far, and with the vibrant contestation of the EU project at the foreground of the electoral narrative, the 2014 EP elections provides a unique opportunity for mapping EP candidates' use of Twitter. Although EP elections traditionally have been dominated by national politics, with European politics playing, at best, a marginal role (Schmitt, 2005; Reif and Schmitt, 1980), the increased contestation of the European project brought forward the politicisation of European issues. Our main expectation is that the growing importance of the EU topic in EP elections will be captured by the social media communication centered around the communication of the MEP candidates.

\subsection{Spitzenkandidaten and the EU's First "Presidential" campaign}

A novelty of the 2014 EP election campaign was the system of Spitzenkandidaten, also known as list-leading candidates. For the first time in the history of EP elections, EP party 
groups had the chance to nominate their candidate for the Presidency of the European Commission. This move was expected both to personalize and politicise the EP elections campaign and also to increase the democratic legitimacy of the Union (Hobolt, 2014; Schmitt et al., 2015). Consequently, the list leading candidates were expected to play a major role in the campaign, an expectation which to a large degree they fulfilled. Even if the candidates had rather limited campaign budgets, their substantial ground presence, the nine televised debates between them, and their significant social media presence definitely left a mark (Schmitt et al., 2015). Recent works assessing the impact of the introduction of list-leading candidates indicates that their presence and campaign efforts improved election turnout (Schmitt et al., 2015) and raised attention on the ongoing debate over the legitimacy of the EU (Rohrschneider et al., 2015).

Two of the three major Spitzenkandidat had an active presence on Twitter. S\&D's leading candidate Martin Schulz had 110,000 Twitter followers and almost 250,000 mentions, followed by ALDE's eading candidate Guy Verhofstadt with 26,000 followers and 105,000 mentions, were the most active leading candidates during the campaign. At the same time it is worth mentionign that the leading candidate of the European People's Party (EPP) JeanClaude Juncker did not set up an official Twitter account. During the May 15 televised leaders' debate, broadcast live across the whole of the EU, the "\#TELLEUROPE" hashtag was trending in Austria, Belgium, France, Germany, Greece, Ireland, Netherlands and the UK, and was mentioned in 110,000 tweets ${ }^{1}$. The May 15 leaders' debate, furthermore, actively encouraged viewers to pose questions for the leaders via Twitter. As we will see below, the significant Twitter presence of the Spitzenkandidaten and the Twitter buzz over the May 15 debate had a significant impact of the election discourse over social media.

\section{European-level versus national political competition}

EP elections are traditionally referred to as "second order" elections because they are thought to focus on national, rather than European-level issues (van der Eijk and Franklin, 1996;

\footnotetext{
${ }^{1}$ Source: http://www3.ebu.ch/contents/news/2014/05/ebu-makes-history-with-the-eurov . html
} 
Hix and Marsh, 2007; Schmitt, 2005). In earlier stages of the European project, as most political parties converged toward an EU-positive position, the EU dimension was far less salient to domestic and European electoral competition (Hooghe et al., 2002). In this context, previous research found that attitudes towards the EU were at best weak predictors of electoral behaviour in EP elections (de Vries and Hobolt, 2012; Hobolt and Wittrock, 2011). But this does not mean that attitudes toward the EU are absent from EP elections. On the contrary, attitudes towards the EU sum up into an independent European dimension of political competition that ranges from outright opposition to full support of EU integration processes (Benoit and Laver, 2012; Gabel and Hix, 2002; McElroy and Benoit, 2007). The origins of its rise can be identified in the early 1990s when the increasing contestation of the European project brought an end to the years of "permissive consensus" (Hooghe and Marks, 2009). In more recent years non-mainstream parties (mainly radical left and radical right parties) managed to exploit opposition towards the EU by promoting a Euroskeptic stance and polarizing the EU dimension, at the same time increasing its salience as a political issue (de Vries and Hobolt, 2012; Hobolt and de Vries, 2015; Rovny, 2012). It is this process that since the $2004 \mathrm{EP}$ elections (at least partly) fuelled the electoral success of what by now are generally referred to as Euroskeptic parties (De Vries and Edwards, 2009).

The economic and political crisis that preceded the 2014 EP elections and the associated debates about the future of the Eurozone, the bailout of debtor states, the austerity measures imposed by the EU, ECB and IMF, and their combined economic consequences, only further fuelled the rise of EU dimension. Even before the 2014 EP election, debates over the future of the EU played an important role in the Dutch and Greek legislative elections, with the positions that parties taking on Europe having decisive effects on their electoral fortunes.By the 2014 EP elections, debates over how to handle financial crises in the eurozone, migration policies, and other regulations had very effectively roused the "sleeping giant" of EU politics (van der Eijk and Franklin, 2004) as a political issue.

Here we examine the competing discourses of traditional national left-right issues versus European issues as they were reflected in social media usage during the campaign. If the 
dimension of contestation is European, rather than primarily about national issues, then we would expect to observe three specific patterns, in the usage, patterns, and content of social media communication.

1. The adoption and usage of social media for campaigning can be be explained by preferences on European policy, versus national (left-right) policy. This would be evidence that the elections, and by extension, political communication during the elections is linked through policy preferences to European issues, rather than simply extending national politics.

Until the 2014 EP elections, such a common public sphere was missing. What we have been witnessing is, at best, an increasing "parallelization" of public spheres across Europe, where similar issues are being debated at the same time (Kriesi and Grande, 2014; Koopmans and Statham, 2010), but which do not sum up to an EU wide debate. The spread of social media has the potential to change this state of affairs. Therefore we would also expect that:

2. The communication patterns of social media were transnational and European, sharing linkages across many countries, rather than taking place on topics and through networks that are entirely contained within national contexts. Specifically,

(a) Language barriers notwithstanding, a European level of political discourse as measured in social media communication implies that there are topics in common and that citizens are communicating across borders and even languages on issues of common - and European - interest.

(b) European-wide political communication will be most evident in social media usage surrounding the list-leading candidates (Spitzenkandidaten), those who for the first time in 2014 were able to campaign directly as their party groups' chosen candidates for the presidency of the European Commission.

Finally, using appropriate text analysis tools, we should be able to discern patterns in the content of social media communications: 
3. The content of social media communications, as measured by the expressions of proand anti-EU statements, and by positive and negative sentiment, is more associated to patterns of preferences around the EU dimension, than to differences on national political issues or general left-right policy views.

Taken together, these expectations form specific, testable propositions for better understanding how political developments at the European level are reflected in social media and, importantly, for exploring how these new political communication tools are embedded in candidates' political communication strategies in an election with many new and unusual elements. Before testing for evidence of these patterns, we briefly describe our dataset.

\section{Data: Twitter from the 2014 EP Elections}

The data used in this paper was collected as part of the European Elections Study 2014, Social Media Study. We identified and collected the candidate lists of almost all the parties who competed in the 2014 EP elections..$^{2}$ We checked which of the identified candidates had a Twitter and/or a Facebook accounts and linked these to data on all MEP candidates on record. In total, we found that a total of 3,180 out of 15,353 identified MEP candidates (21\%) had a presence on Twitter.

Using a platform with direct access to the Twitter firehose ${ }^{3}$, we collected all the social media communication centred around the candidates 4 . In the specific case of Twitter, this implied every tweet, re-tweet and response of a candidate as well as all the responses to these tweets. We also collected all the tweets that mentioned the candidates in any form. The data collection procedure lasted for 4 weeks from May 3, 2014 until June 1, 2014, covering the last 3 weeks of the electoral campaign and the week following the elections. This produced a database consisting of approximately 3.8 million tweets that we believe accurately represents the total extent of election-related political communication through

\footnotetext{
${ }^{2}$ This process was made easier because elections to the EP are from party lists, and we were able to obtain the lists of all named candidates.

${ }^{3}$ This access was provided to our partners at TNS Opinion, through the Vigiglobe platform.

${ }^{4}$ It needs to be mentioned that 430 accounts were only identified based on subsequent checks made after the election date. Therefore we were only able to collect the social media communication of 2750 candidate (i.e $86 \%$ of the total number)
} 
Twitter during 2014 EP elections campaign. In Table 1 summarizes this data and the parties, candidates, and countries which it covers.

There is considerable variation of candidate Twitter adoption that begins with extremely low adoption rates, such as in Bulgaria (8\%), the Czech Republic (6\%), but also Portugal (7\%), to very high, such as in Ireland (73\%), Sweden (67\%), Finland (67\%) and the Netherlands (66\%). These findings partly confirm previous research on new media adoption and web campaigning by EU politicians about a "North-South divide" across Europe (Vergeer et al., 2012) in terms of activity. Divides in Twitter activity are also quite evident on the map whereby the overall activity appears as much less voluminous in East European countries and Greece in comparison, for example, to the UK, Italy and the Netherlands. Although the overall pattern (see Figure 1) pattern is incomplete (due to limited geolocation information in tweets), it does seem that in Southern and Eastern European countries fewer EU politicians own a Twitter account in comparison to their counterparts in Northern European countries.

Tweets occurred in a total of 34 languages, with Spanish being the top language of all Tweets (29.9\%), followed by Italian (19\%), English (17\%), and French (13.3\%). Among candidates' Tweets, English led at 21.2\%, followed by Spanish, Italian, and French at 16\%, $15 \%$, and $9 \%$ respectively. Approximately $1.2 \%(44,723)$ of all Tweets were undetectable from a language standpoint, as they contained only URLs, hashtags, or Twitter user names,

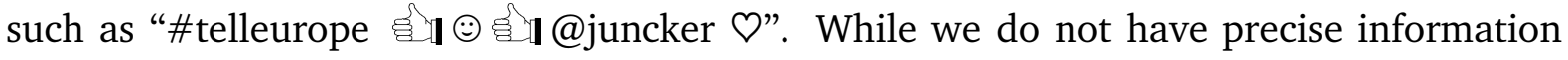
about the national location of every Tweet, we do know what country candidates were from. Of candidate Tweets using English, only 76\% came from the United Kingdom and Ireland. Another 4.6\% of all English Tweets came from Austria, 3.6\% from the Netherlands, and $2.6 \%$ and $2.0 \%$ from Germany and Finland. Of the countries using primarily their own languages, after the English-speaking countries of the UK and Ireland using 96\% English Tweets each, France was the next highest, with $94.7 \%$ of its candidates Tweeting in French, followed by $91.7 \%$ of Italian candidates communicating in Italian and $89.5 \%$ of Polish candidates using Polish.

The metadata of tweets from users who have enabled geolocation on their Twitter de- 


\begin{tabular}{|c|c|c|c|c|c|}
\hline Country & $\begin{array}{r}\text { Total } \\
\text { Parties }\end{array}$ & $\begin{array}{r}\text { Total } \\
\text { Candi- } \\
\text { dates }\end{array}$ & $\begin{array}{c}\text { Cands } \\
\text { w/Twitter }\end{array}$ & $\begin{array}{c}\text { \% Using } \\
\text { Twitter }\end{array}$ & $\begin{array}{r}\text { Total } \\
\text { Tweets }\end{array}$ \\
\hline \multicolumn{6}{|l|}{ By country } \\
\hline Ireland & 7 & 41 & 30 & 73.2 & 7300 \\
\hline Sweden & 12 & 373 & 249 & 66.8 & 36483 \\
\hline Finland & 9 & 249 & 166 & 66.7 & 16797 \\
\hline Netherlands & 10 & 345 & 229 & 66.4 & 42109 \\
\hline Italy & 8 & 653 & 355 & 54.4 & 70414 \\
\hline Denmark & 8 & 100 & 54 & 54 & 5513 \\
\hline United Kingdom & 9 & 749 & 341 & 45.5 & 66921 \\
\hline Latvia & 6 & 170 & 64 & 37.6 & 4220 \\
\hline Slovenia & 10 & 118 & 44 & 37.3 & 4150 \\
\hline Luxembourg & 8 & 54 & 19 & 35.2 & 14 \\
\hline Cyprus & 5 & 48 & 15 & 31.2 & 587 \\
\hline Estonia & 7 & 88 & 26 & 29.5 & 1115 \\
\hline Austria & 7 & 348 & 78 & 22.4 & 19876 \\
\hline Greece & 9 & 544 & 118 & 21.7 & 7460 \\
\hline Belgium & 13 & 182 & 38 & 20.9 & 2345 \\
\hline Poland & 8 & 1286 & 249 & 19.4 & 13696 \\
\hline Germany & 7 & 946 & 163 & 17.2 & 16772 \\
\hline Lithuania & 9 & 257 & 33 & 12.8 & 507 \\
\hline Spain & 9 & 2105 & 266 & 12.6 & 76784 \\
\hline France & 7 & 3735 & 411 & 11 & 38361 \\
\hline Slovakia & 10 & 334 & 36 & 10.8 & 1193 \\
\hline Croatia & 7 & 275 & 26 & 9.5 & 876 \\
\hline Hungary & 6 & 322 & 29 & 9 & 218 \\
\hline Romania & 10 & 580 & 48 & 8.3 & 411 \\
\hline Bulgaria & 7 & 286 & 23 & 8 & 830 \\
\hline Portugal & 5 & 336 & 22 & 6.5 & 4482 \\
\hline Czech Republic & 9 & 829 & 48 & 5.8 & 1867 \\
\hline TOTAL & 222 & 15353 & 3180 & & 441301 \\
\hline \multicolumn{6}{|c|}{ By incumbency status } \\
\hline Non-incumbent & & 14,607 & 2641 & $18 \%$ & \\
\hline Incumbent & & 746 & 539 & $72 \%$ & \\
\hline Total & & 15,353 & 3180 & $21 \%$ & \\
\hline
\end{tabular}

Table 1: Candidates and Election-Related Twitter Communication during the 2014 EP Elections, by Country (updating candidates accounts). 


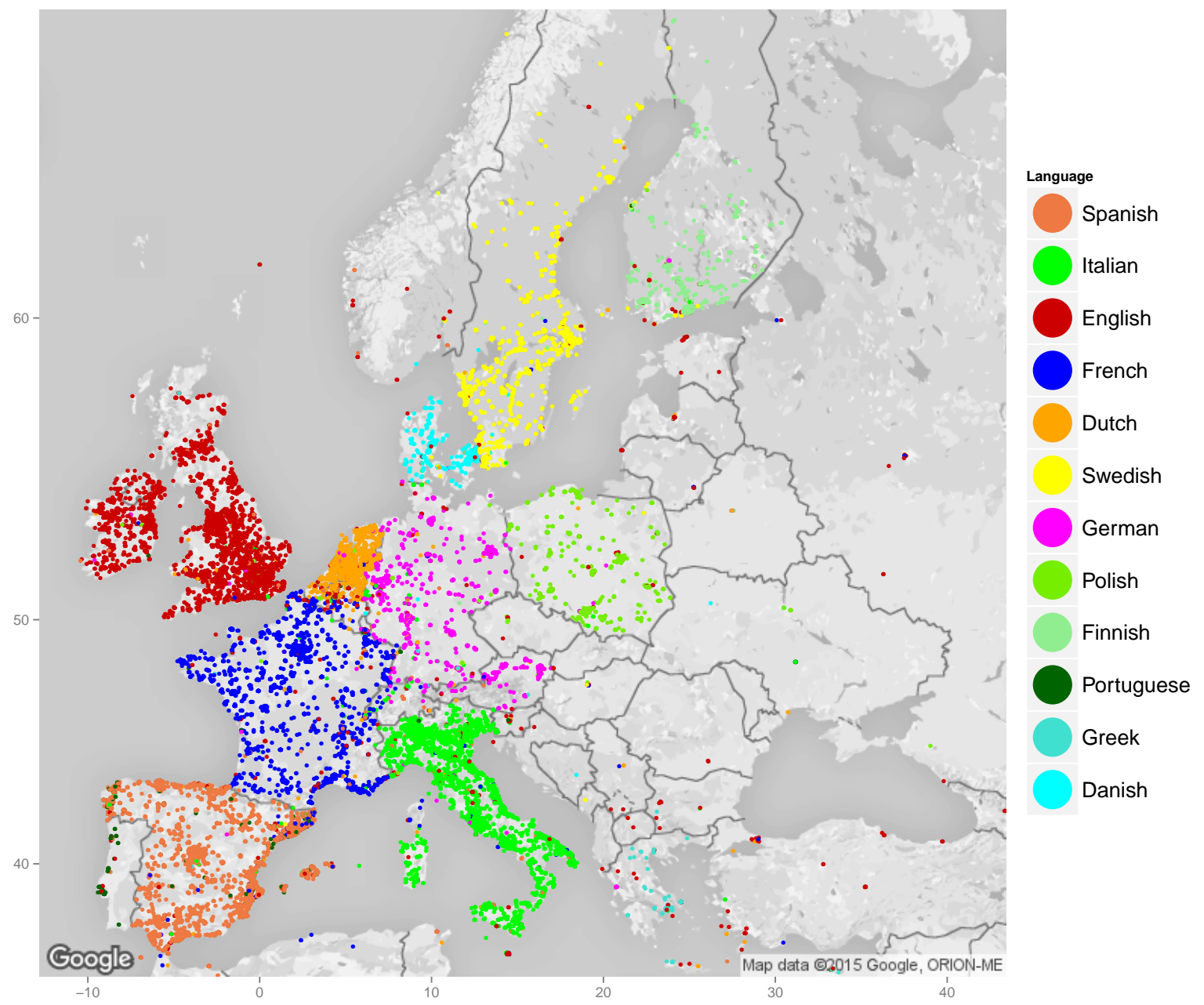

Figure 1: Location of tweets with co-ordinate information enabled, colored by the language of the tweet. 
vices contain geographical coordinates. Past estimates suggest that the proportion of tweets containing this volunteered geographic information is around 1-1.5\%, and that this proportion is growing (Crampton et al., 2013). 5. In our dataset, $1.98 \%$ of tweets contained geolocation information. Figure 1 shows the location of these tweets, colored by the detected language of the tweet. The percentage of tweets that contained geo-location information varied by language, from around 1.5\% (Spanish and French) to 4.7\% (Danish). The clear pattern linking languages to national contexts indicates that social media engagement primarily takes place in the language of the country from which it originates.

\section{Explaining Twitter Adoption and Usage By Candidates}

\subsection{Patterns of Twitter Adoption}

Before analyzing the political messages in Twitter content from the 2014 EP elections campaign, it is important to establish in more general terms who tweets. Regarding the personal characteristics of the candidates, previous research shows that gender and the candidate's status strongly predict both whether a candidate has a Twitter account as well as the level of Twitter usage. Lorenzo-Rodríguez and Madariaga (2015); Vergeer et al. (2011) found that incumbency status is one of the most important predictors of a candidate's Twitter presence. Our analysis confirms this finding (see Tables 1 and 2): Candidates who were sitting MEPs in 2014 were about four times more likely to have a Twitter account, and six times more likely if they had also been incumbent in 2009. As we will see below (Figure 5), furthermore, among the candidates who had a Twitter account, incumbents were also sent more Tweets per day on average than non-incumbents. A second personal characteristic that we take into account is gender and, while previous research offers mixed results with regards to its effects (Jungherr, 2014b), we show here (see results in Table 1 and Model 2)

\footnotetext{
${ }^{5}$ Technological, social and behavioural factors mean that the presence or absence of geolocation data varies cross-nationally and is biased towards urban users, even after accounting for population density (Hecht and Stephens, 2014)so we do not take it as representative sample. German is not underrepresented in the geolocation data, suggesting that the relative sparseness of German tweets is a result of less social media engagement in the elections than in other major European languages.
} 

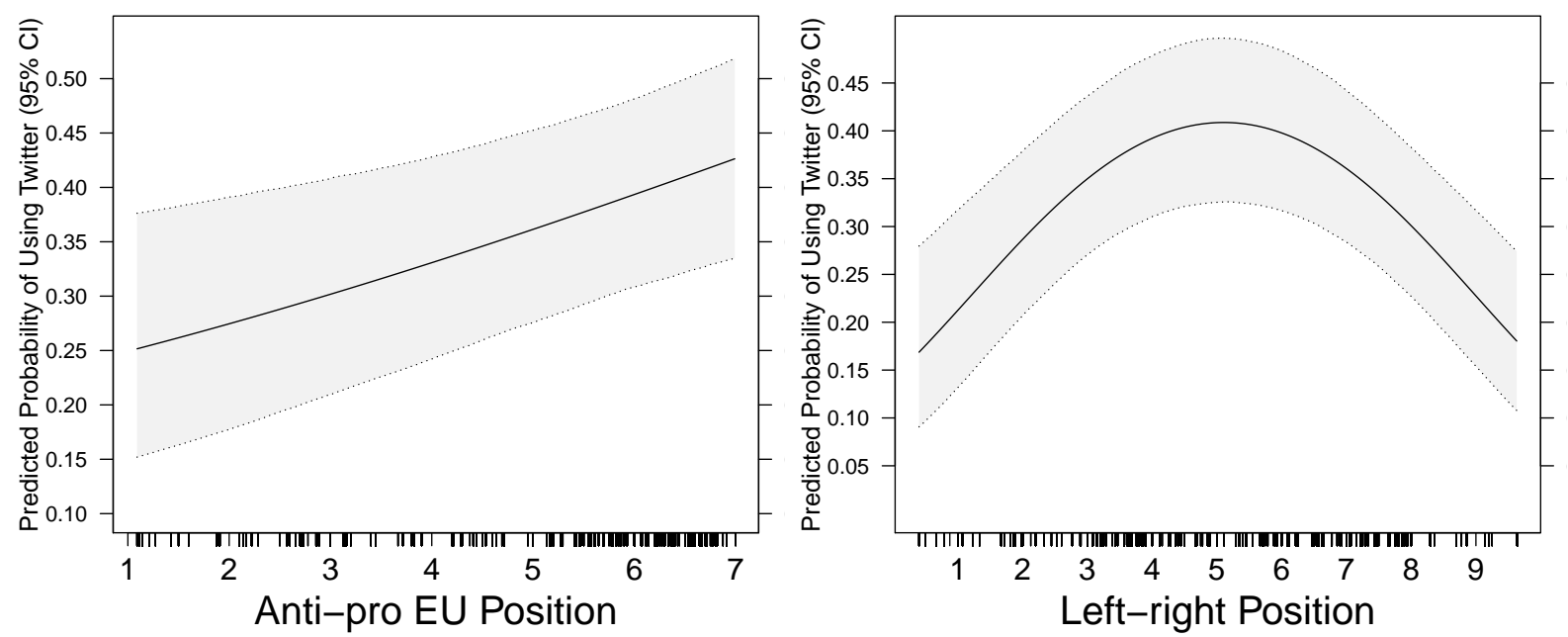

Figure 2: Effect of Candidate Party's Left-right position on the predicted probability of having a Twitter Account. Predicted probabilities computed based on Model 5 respectively Model 4 in Table 2. Predicted values computed while holding all continuous variable at the mean and all categorical variables at zero.

that male candidates are about $20 \%$ more likely to have Twitter accounts ${ }^{6}$.

We also tested whether the policy positions of a candidate's party predicted their adoption of Twitter. For measuring policy positions, we linked candidates' parties to the policy positions on EU positioning (a 7 point scale) and to general left-right positioning (11 point scale) from the 2010 Chapel Hill expert survey (Bakker et al., 2012). The results in Table 1 allow for a quadratic link in left-right policy to reflect the influences of extremism on either side, and a linear link for anti- versus pro-EU preferences. We also added variables that control for the size of parties (measured as the share of votes that a given party obtained in the 2014 EP elections) and for the rate of Internet penetration in a give country (this follows Lorenzo-Rodríguez and Madariaga, 2015). We do this by using a series of multilevel regression models which take into account the appropriate structure of this additional data (i.e. candidates nested into parties nested into countries) 7 .

The results reveal a clear tendency for Twitter adoption to increase with the degree of pro-Europeanness of a candidate. Specifically, moving one position on the seven point antipro EU scale increases the propensity to find a candidate with Twitter account by between

\footnotetext{
${ }^{6}$ In our dataset, we had no data on the candidate gender for $39 \%$ of the candidates.

${ }^{7}$ All models were estimate using the glmer command in the R package lmer. While country level variables is (i.e. Internet penetration) grand mean centered, for ease of interpretation we chose to present an analysis in which the party level predictors are not centered. Nevertheless, grand mean centering these predictors reveals a substantially identical pattern of results.
} 


\begin{tabular}{|c|c|c|c|c|c|}
\hline & $(1)$ & $\begin{array}{c}\text { Dependent var } \\
(2)\end{array}$ & $\begin{array}{c}\text { le: Candidate Has } \\
\text { (3) }\end{array}$ & $\begin{array}{c}\text { Twitter Account } \\
\text { (4) }\end{array}$ & $(5)$ \\
\hline \multicolumn{6}{|l|}{ Fixed effects } \\
\hline Constant & $\begin{array}{c}0.251^{* * *} \\
(0.175,0.361)\end{array}$ & $\begin{array}{c}0.321^{* * *} \\
(0.234,0.440)\end{array}$ & $\begin{array}{c}0.178^{* * *} \\
(0.100,0.318)\end{array}$ & $\begin{array}{c}0.134^{* * *} \\
(0.061,0.296)\end{array}$ & $\begin{array}{c}0.158^{* * *} \\
(0.070,0.360)\end{array}$ \\
\hline MEP 2014 & $\begin{array}{c}7.191^{* * *} \\
(5.847,8.843)\end{array}$ & $\begin{array}{c}4.492^{* * *} \\
(3.660,5.512)\end{array}$ & $\begin{array}{c}3.432^{* * *} \\
(2.725,4.324)\end{array}$ & $\begin{array}{c}3.391^{* * *} \\
(2.693,4.271)\end{array}$ & $\begin{array}{c}3.415^{* * *} \\
(2.711,4.300)\end{array}$ \\
\hline MEP 2009 & $\begin{array}{c}5.713^{* * *} \\
(4.415,7.392)\end{array}$ & $\begin{array}{c}4.261^{* * *} \\
(3.309,5.487)\end{array}$ & $\begin{array}{c}3.388^{* * *} \\
(2.540,4.519)\end{array}$ & $\begin{array}{c}3.430^{* * *} \\
(2.572,4.572)\end{array}$ & $\begin{array}{c}3.408^{* * *} \\
(2.554,4.546)\end{array}$ \\
\hline MEP gender & & $\begin{array}{c}1.201^{* * *} \\
(1.087,1.328)\end{array}$ & & & \\
\hline EU position (party) & & & $\begin{array}{c}1.200^{* * *} \\
(1.105,1.303)\end{array}$ & & $\begin{array}{c}1.148^{* * *} \\
(1.044,1.264)\end{array}$ \\
\hline Left-right (party) & & & & $\begin{array}{c}1.791^{* * *} \\
(1.344,2.388)\end{array}$ & $\begin{array}{c}1.211 \\
(0.824,1.780)\end{array}$ \\
\hline Left-right $^{2}$ (party) & & & & $\begin{array}{c}0.944^{* * *} \\
(0.920,0.970)\end{array}$ & $\begin{array}{c}0.981 \\
(0.946,1.018)\end{array}$ \\
\hline Party size & & & $\begin{array}{c}2.924 \\
(0.729,11.734)\end{array}$ & $\begin{array}{c}2.996 \\
(0.801,11.201)\end{array}$ & $\begin{array}{c}1.999 \\
(0.565,7.072)\end{array}$ \\
\hline $\begin{array}{l}\text { Internet penetration } \\
\text { (country) }\end{array}$ & $\begin{array}{c}1.071^{* * *} \\
(1.040,1.104)\end{array}$ & $\begin{array}{c}1.062^{* * *} \\
(1.031,1.094)\end{array}$ & $\begin{array}{c}1.078^{* * *} \\
(1.042,1.114)\end{array}$ & $\begin{array}{c}1.074^{* * *} \\
(1.039,1.109)\end{array}$ & $\begin{array}{c}1.076^{* * *} \\
(1.041,1.112) \\
\end{array}$ \\
\hline \multicolumn{6}{|l|}{ Random effects (variance) } \\
\hline Intercept (party) & & & 2.012 & 1.592 & 2.823 \\
\hline EU position (party) & & & 0.060 & & 0.032 \\
\hline Left-right (party) & & & & 0.017 & 0.015 \\
\hline Party size & & & 8.47 & 6.331 & 4.282 \\
\hline Intercept (country) & 0.825 & 0.602 & 0.733 & 0.694 & 0.745 \\
\hline Internet penetration & 0.001 & 0.001 & 0.001 & 0.001 & 0.001 \\
\hline Observations (Candidates) & 15,361 & 9,335 & 6,298 & 6,298 & 6,298 \\
\hline Observations (Party) & & & 174 & 174 & 174 \\
\hline Observations (Country) & 27 & 27 & 27 & 27 & 27 \\
\hline Log Likelihood & $-6,145.901$ & $-5,021.652$ & $-3,404.106$ & $-3,404.993$ & $-3,399.572$ \\
\hline Akaike Inf. Crit. & $12,305.800$ & $10,059.310$ & $6,838.212$ & $6,841.987$ & $6,841.144$ \\
\hline Bayesian Inf. Crit. & $12,359.280$ & $10,116.440$ & $6,939.432$ & $6,949.955$ & $6,982.852$ \\
\hline
\end{tabular}

Note:

${ }^{*} \mathrm{p}<0.1 ;{ }^{* *} \mathrm{p}<0.05 ;{ }^{* * *} \mathrm{p}<0.01$

Table 2: Predicting MEP Candidates' Adoption of Twitter. Multilevel logistic regression with exponentiated coefficients and confidence intervals. 
15 and 20 percent (Models 3 and 5). As depicted in Figure 2, candidates of the most pro-EU parties are almost twice as likely to have a Twitter account when compared to the candidate of anti-EU parties, all else being equal. In addition, mainstream party candidates on the general left-right spectrum were also most likely to adopt Twitter: almost 2.5 times more likely in the center of the left-right spectrum than at the extremes (right panel of Figure 2). We know from a great deal of previous research, of course, that there is a strong relationship between left-right extremity and anti-EU positions (McElroy and Benoit, 2007). In Model 5 which includes both, we note that the effect of EU positioning remains statistically significant while that of left-right positioning does not. When it comes to structuring the Twitter adoption of European candidates, attitudes towards the EU are more predictive than that national-level left-right issues, suggesting that our first expectation is confirmed.

A possible explanation why incumbent MEPs are more likely to adopt Twitter is that they may have the staff or the established party or party group support to set up and maintain social media accounts. For less mainstream challengers, however, social media offers a direct route to campaign communication that it far less expensive than more traditional methods of advertising. With this in mind, the fact that anti-EU parties coming from the fringes of the ideological spectrum are less likely to take to Twitter is counter-intuitive and goes against previous expectations (Jungherr, 2014b). A possible explanation, given that social media maintenance and consultancy is a comparatively resource intensive effort, is that mainstream parties simply have more resources. Even in the context of the low salience EP elections, mainstream pro-EU parties have at their disposal a larger pool of (semi)professional eligible candidates. At the same time even if anti-EU parties have at the head of the list their well known party leaders (see example of Front National and UKIP), the bulk of their candidates were (most likely) never before in the position to run for public office. Thus it is not surprising that such candidates may know little about the benefits of new media adoption and prefer to channel their few resources towards on more direct voter outreach, or they simply lack the know-how to create a public profile, which involves establishing a social media presence. Nevertheless, it is worth examining here whether the patterns of usage follow the patterns already shown predicting adoption. 


\begin{tabular}{lccc}
\hline \hline & \multicolumn{3}{c}{ Dependent variable: } \\
\cline { 2 - 4 } & $(1)$ & $(2)$ & $(3)$ \\
\hline \hline \multirow{2}{*}{ Fixed effects } & & & \\
Intercept & $148.069^{* * *}$ & $151.308^{* * *}$ & $173.600^{* * *}$ \\
MEP 2014 & $(102.509,213.877)$ & $(104.665,218.737)$ & $(113.200,266.225)$ \\
& $1.520^{* * *}$ & $1.553^{* * *}$ & $1.553^{* * *}$ \\
MEP gender & $(1.506,1.534)$ & $(1.539,1.567)$ & $(1.539,1.568)$ \\
& & 0.996 & 0.996 \\
EU position (candidate) & $0.916^{* * * *}$ & $(0.988,1.003)$ & $(0.988,1.003)$ \\
& $(0.911,0.921)$ & $0.914^{* * *}$ & $0.914^{* * *}$ \\
Left-right (candidate) & $1.201^{* * *}$ & $(0.909,0.919)$ & $(0.909,0.919)$ \\
& $(1.187,1.215)$ & $(1.182,1.210)$ & $1.196^{* * *}$ \\
Left-right ${ }^{2}$ (candidate) & $0.976^{* * *}$ & $0.976^{* * *}$ & $(1.182,1.210)$ \\
Party size & $(0.975,0.977)$ & $(0.975,0.977)$ & $0.976^{* * *}$ \\
Internet penetration & & $0.975,0.977)$ \\
(country) & 1.019 & 1.019 & 0.329 \\
\hline
\end{tabular}

Random effects (variance)

\begin{tabular}{lccc} 
Intercept (party) & 0.591 & 0.598 & 0.730 \\
Party size & & & 2.864 \\
Intercept (country) & 0.348 & 0.349 & 0.350 \\
Internet penetration & 0.001 & 0.001 & 0.001 \\
\hline Observations (Candidate) & 1,349 & 1,336 & 1,335 \\
Observations (Party) & 124 & 124 & 123 \\
Observations (Country) & 18 & 18 & 18 \\
Log Likelihood & $-149,773.300$ & $-147,805.100$ & $-147,798.800$ \\
Akaike Inf. Crit. & $299,566.700$ & $295,632.200$ & $295,625.700$ \\
Bayesian Inf. Crit. & $299,618.800$ & $295,689.400$ & $295,698.400$ \\
\hline \hline
\end{tabular}

Note: $\quad{ }^{*} \mathrm{p}<0.1 ;{ }^{* *} \mathrm{p}<0.05 ;{ }^{* * *} \mathrm{p}<0.01$

Table 3: Poisson regression of the Number of Tweets per candidate, among candidates with Twitter accounts. Coefficients and confidence intervals are exponentiated. 


\subsection{Patterns of Twitter usage}

In Table 3 we predict the volume of Tweets per candidate. We adopt a modeling strategy similar to the one presented in 3 with the difference that in this case we can use the the policy position of the candidates calculated from the Twitter follower graph (Barberá, 2015; Barberá et al., 2015). An interesting and contrary pattern emerges to that shown above for the probability of having a Twitter account. Among candidates with Twitter accounts, it turns out that the number of total Tweets sent by users was negatively related to the level of pro-EU positioning. This patters is clearly illustrated in Figure 3 where we plot the marginal effects of changes in these two policy variables. Controlling for left-right ideology, candidates from anti-EU parties were more active on Twitter, when they had Twitter accounts, even if the above analysis shows that they were less likely to have such accounts.

While this effect runs opposite to the finding of the relationshiop of EU positioning to Twitter adoption, it remains in line with our previous expectations, that candidates of anti-EU parties are a very vocal minority on Twitter. Most anti-EU parties simply lack the numbers or organizational capacity to organize and support widespread adoption of social media adoption by their candidates. But for candidates who did embrace such channels, they tended to use them disproportionately as a cheap and accessible platform to communicate their views and to reach followers. Furthermore, given that anti-EU stances are much more popular among Twitter users (see Figure 10), pro-EU candidates may have tempered their expression of pro-EU sentiment or reduced their overall levels of engagement with the public on Twitter. Previous research has shown that when the mood of the public is not favorable towards the EU, parties tend to downplay their attachment towards the EU (Popa and Dumitrescu, 2015). Anti-EU candidates are both more motivated to be active on Twitter and benefit from a public mood that encourages them to engage with the public by expressing their policy stances. 

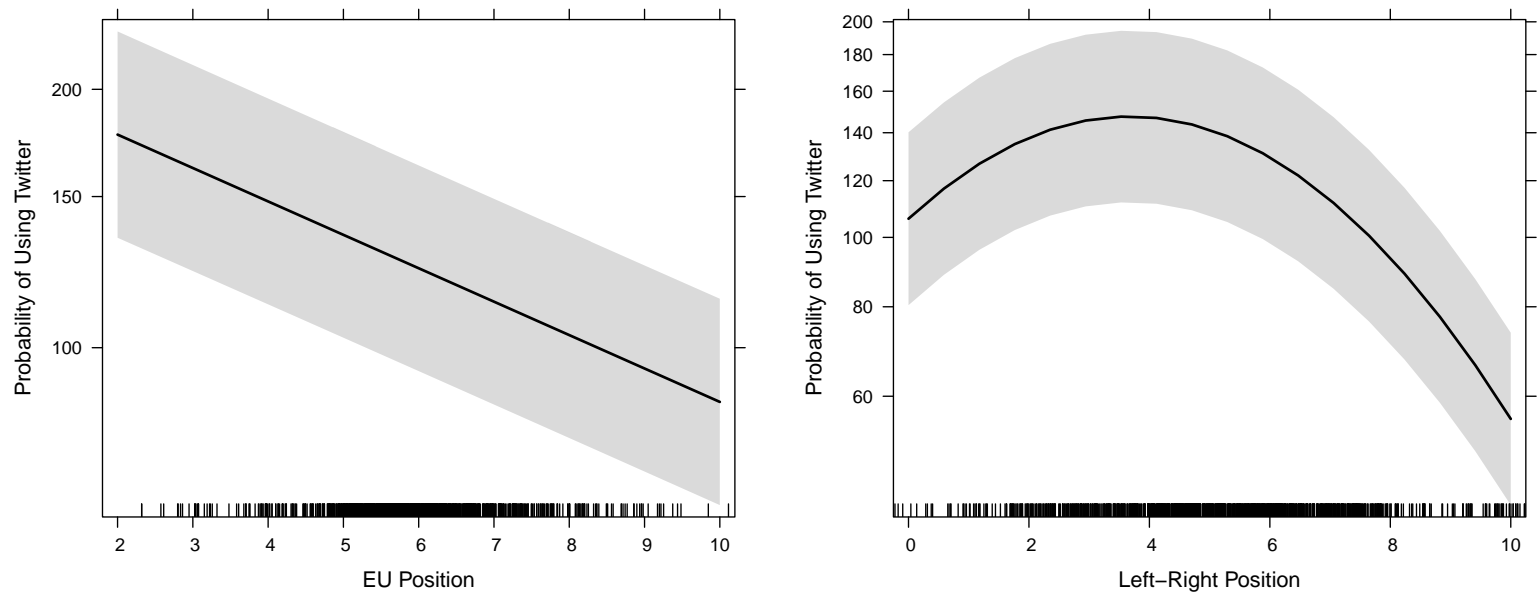

Figure 3: Marginal effects of candidates' parties' policy positions on the predicted Tweet counts, for candidates using Twitter. Predicted probabilities computed based on Model 3 from Table 3 .

\section{Patterns of Social Media Communication}

\subsection{Tweet Type and Volume Throughout the Campaign}

Twitter activity about the election was relatively constant across the period examined, with two exceptions: the May 15 leaders' debate, and the actual elections. Figure 4 shows the overall volume of tweets sent throughout the campaign by tweet type, first for all tweets and secondly for candidates' tweets. Figure 5 complements the picture by showing the mean tweets per day sent by MEP candidates who had Twitter accounts distinguishing between incumbents and non-incumbents. The patterns depicted generally confirm previous findings about the fluctuation in the numbers of Twitter messaging during heated events such as electoral competition or protests (Jungherr and Jürgens, 2014). In terms of overall tweeting intensity, the highlight of the campaign period period was the leaders' TV debate which was broadcasted live in almost all countries and whose organisers encouraged the public to tweet about and event address questions to the candidates via the platform.

The picture when looking at the candidates' tweets is different. The peak in tweeting activity here is reached at the beginning of the election (which with the UK election being earlier than the others varied somewhat) with incumbents being more active than non-incumbents throughout the whole campaign confirming findings provided by extant 


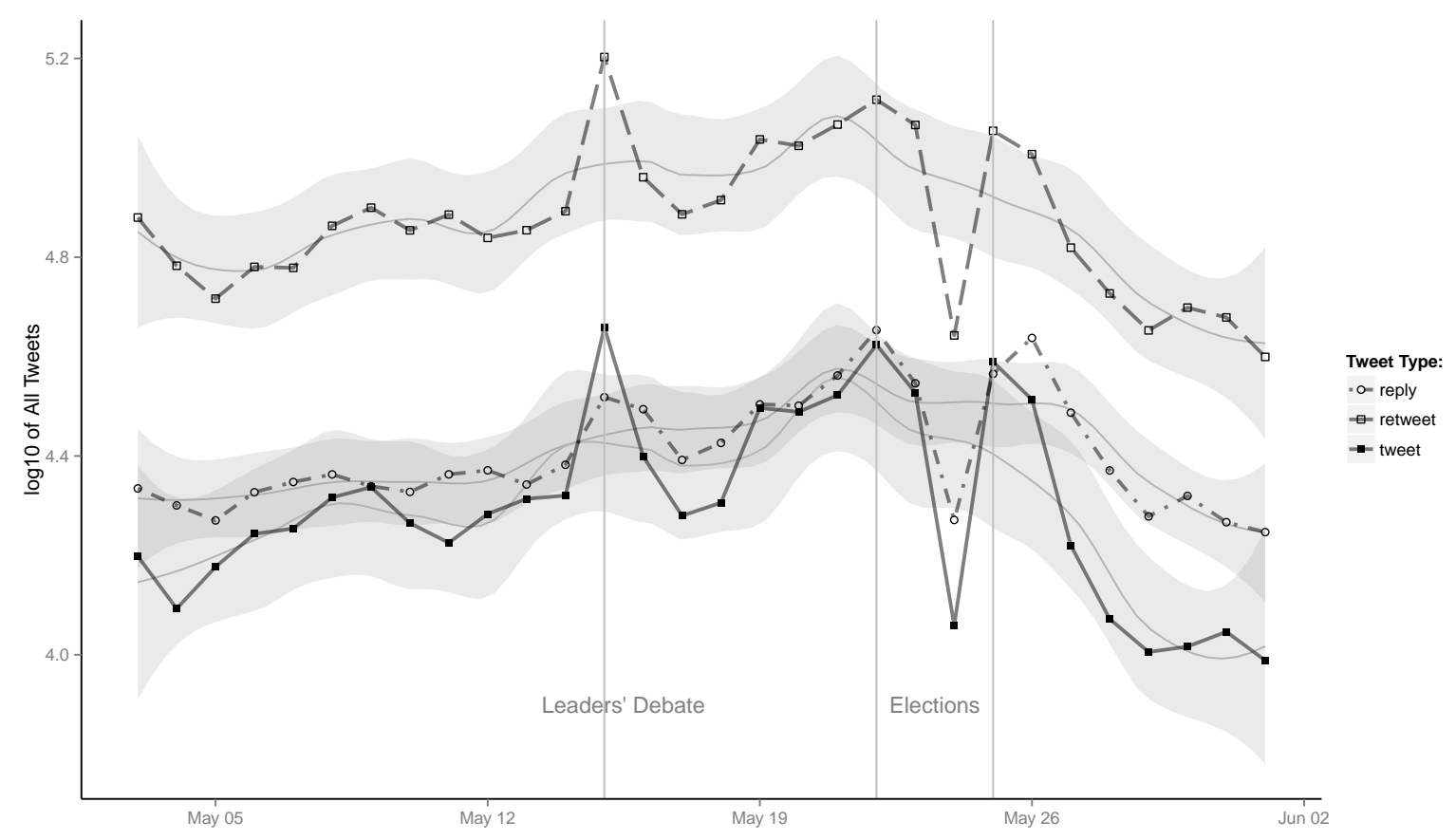

Figure 4: Overall Tweet Volume Throughout the Campaign, by Tweet type.

research (Evans et al., 2014; Lorenzo-Rodríguez and Madariaga, 2015). Although no previous study has asked the question why incumbents are more active than non-incumbents, we speculate that it is probably a combination of having previously used Twitter successfully and having established some sort of presence already along with budgetary availability. Unsurprisingly given previous research (Grant et al., 2010), the highest amount of tweets sent by candidates are actually retweets, while replies (which obviously denote interactivity) are consistently fewer. A spike in replies is observed towards the end of the election, presumably because politicians respond to congratulatory messages, and in a matter of a week the whole Twitter activity effectively dies out. This last is consistent with Larsson (2015) which, examining the extent to which EP elections candidates use Twitter permanently or mainly during campaigns, found that their tweeting is not characterised by any permanence, with most Twitter activities dying out at the end of the election. 


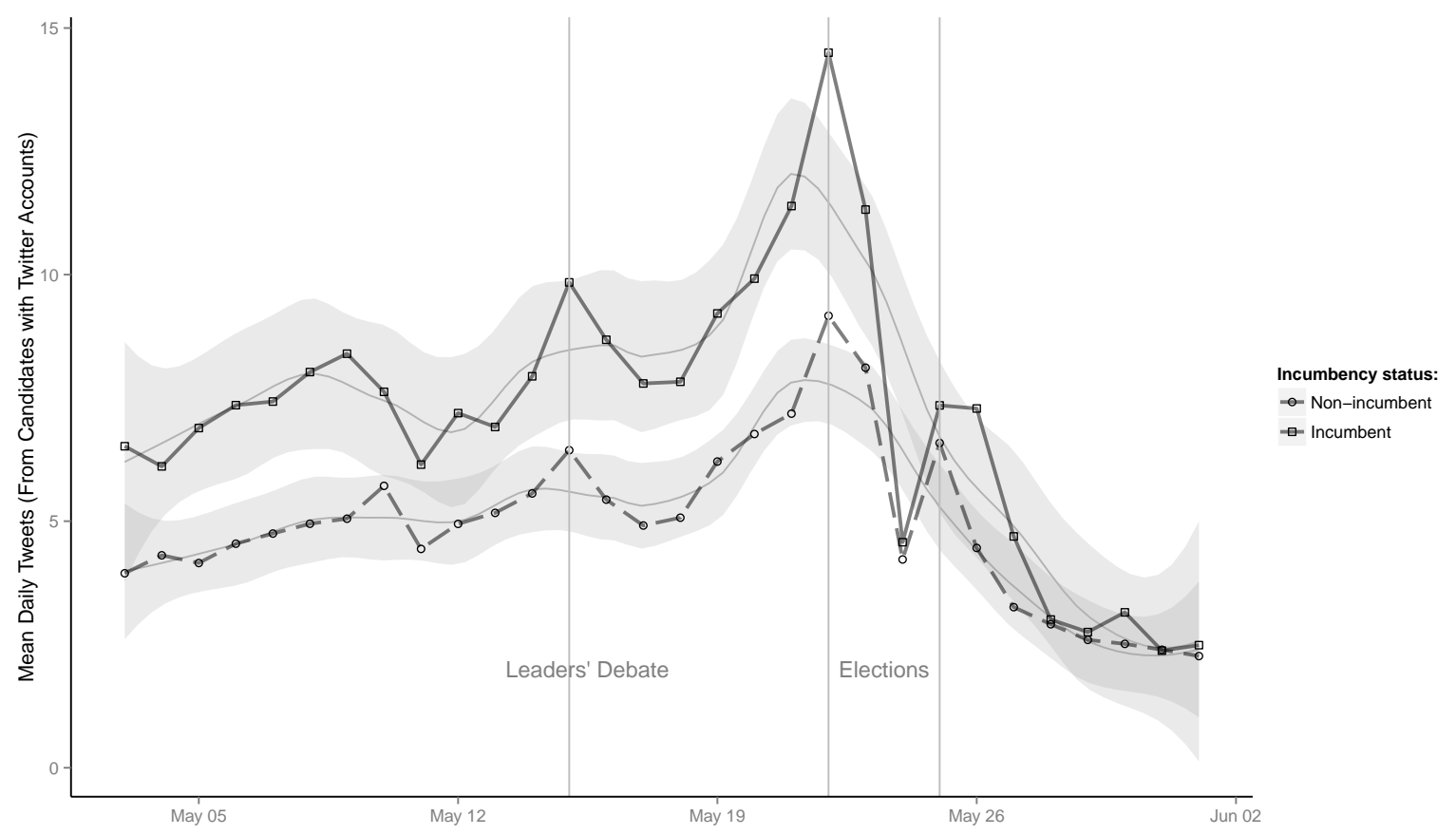

Figure 5: Mean Tweets Per Day Sent by MEP Candidates, from those who had Twitter Accounts, by Incumbency Type.

\subsection{National versus European Dialogue}

\subsection{Most popular hashtags}

What did the conversation across and within countries look like on Twitter? Was it focused predominantly on national issues or was there cross country discussion reflecting something along the lines of a debate on Europe and, if so, who participated in it? We created a country-by-hashtag matrix and used the social network visualisation software package Gephi to depict the networked structure of Twitter conversations. Figure 6 plots a network graph of the debate based on the country-by-hashtag matrix, showing both the connections between countries (left) and between hashtags (right). As we are interested in depicting how hashtag-based conversation unfolds within countries as well as across countries, we use Gephi's Force Atlas 2 algorithm to generate a network visualisation that is optimal for network spatialization, and because it allows for a good representation of networks with different structural densities. After generating the network, we use Gephi's modularity statistic which effectively measures how a network decomposes into modular communities and colours them accordingly. 

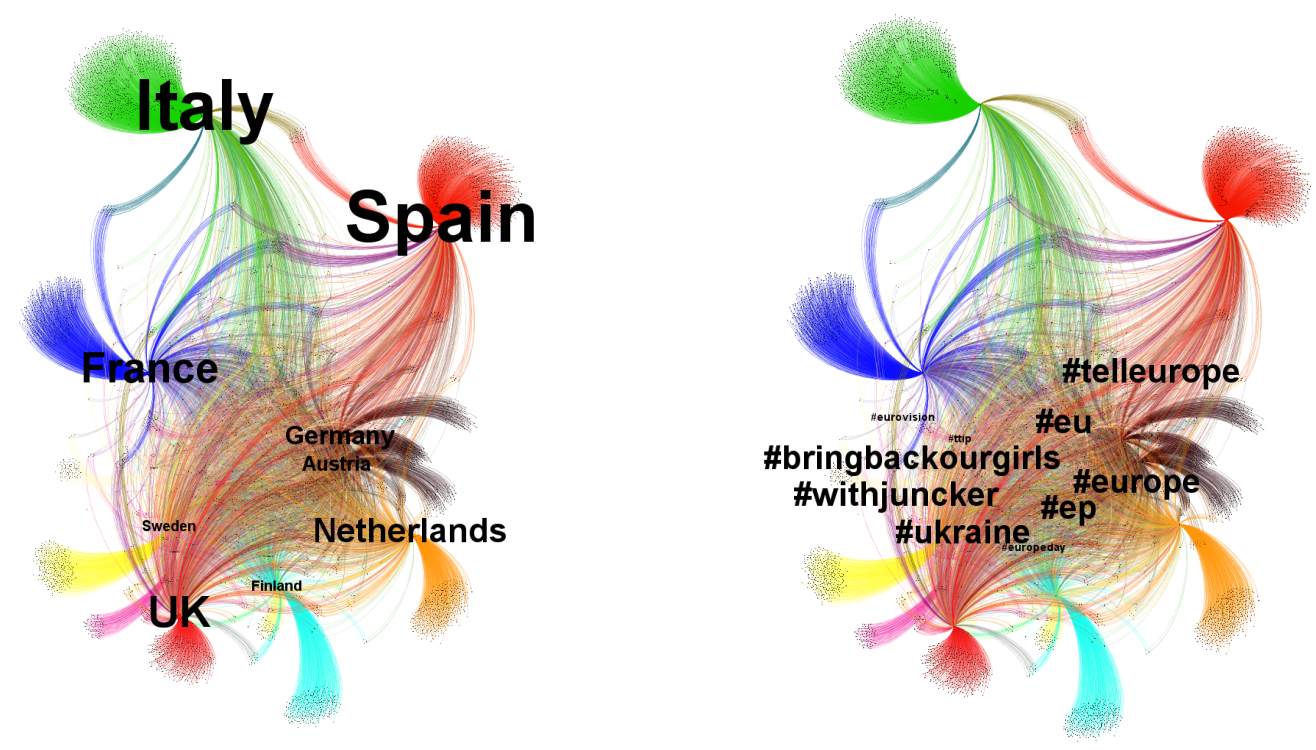

Figure 6: Network graphs depicting within and between country hashtag-based Twitter conversations

In the left panel of Figure 6, revolving around the centre of the network are different communities representing different countries. In the right panel, we remove the country names to focus on the most popular hashtags across countries. As can be seen, especially from the biggest and more voluminous in terms of tweets and hashtags countries, most countries have a clearly identifiable conversation that is unique to the country itself and mainly focuses on national issues (evident from the edges that are unique to, and surround, the country-node, and are headed in the opposite direction from the centre of the network). Table 4 shows the top 10 within-country hashtags in eight countries, along with their percentages, reflecting the most popular topics of conversation in each one of them. Seen in combination with Table 5 , which displays the top 10 most popular between-country hashtags along with their indegree value (denoting the number of countries across which discussion around this particular hashtag is shared), it becomes clear that the there is a conversation around the EP elections (and Europe in general) among all country lists. This finding lends some support to the idea that a European dimension does emerge as a topic of political contestation on Twitter.

The centering of conversation about specific EU-related hashtags is also distinguishable in the network visualisation in Figure 6 by looking at the edges headed towards hashtags 
located at the centre of the network and shared by many country-nodes. In fact, there is not a single country of those listed in Table 4 that doesn't include an EU-related hashtag among the top 10 most popular hahstags. Interestingly, even though in all countries listed in Table 4 the EP elections are among the most discussed issues, one still needs to note that EU-wide hashtags about the election generally rank lower than national-specific hashtags about the election. For example, although the EU-wide hashtags \#eu, \#telleurope, \#europe and \#ep are some of the most popular "connectors" of the debate between different countries (and, when they appear, are depicted in bold in Table 4), none of them tops the list of the top within-country hashtags - although Germany appears to be an exception. Yet, this doesn't mean that discussion regarding the EP elections is not present or popular at the national level. Contrary to our expectations, what we rather see is a form of "parallelization" whereby although similar issues are being debated at the same time in different countries, there is an absence of a common public sphere (Kriesi and Grande, 2014; Koopmans and Statham, 2010). For example, the hashtags \# eurovaalit, \#notreeurope, \#europawahl, \#europa, and \#primaveraeuropa 8 , which take up between $3 \%$ and $31 \%$ of all within-country tweets in Finland, France, Germany, Italy and Spain respectively, still reflect a discussion around the EP elections; just not one that is transnational. This is also evident from our previous analysis of the languages used by candidates, showing that although communication in English (reflecting a trans-national discussion) is clearly present, most communication is in fact taking place in the national language. Overall, this runs contrary to our expectation that social media networking capacities may be able to bridge the debate about the EU, assisting in the creation of what could be thought of as a public sphere.

As one would expect in an electoral campaign environment, one also needs to note the presence of hashtags that make references to specific national parties. Among these, some of the most prominent parties on Twitter are Euroskeptic parties such as UKIP (\#UKIP), Front National (\#fn), True Finns (\#kokomus) Lega Nord(\#lega). This suggests that the social media debate over the legitimacy of the EU is especially prominent in countries where anti-EU parties obtain high electoral scores, and thus especially relevant to the UK and

\footnotetext{
${ }^{8}$ All these hashtags rank in the top 5 most popular within-country hashtags in their respective countries.
} 
France, where UKIP and Front National respectively both scored important victories. Overall, although it cannot be claimed that the social media communication at the time of EP elections reflects exclusively an opposition towards the legitimacy of the EU project, despite the plentiful discussion about the EU and the EP elections, a good chunk of the conversation is indeed oriented towards contesting the EU. This again speaks to the "parallelization" of the public sphere rather than to the existence of a common European public sphere.

Observing the graphs along with the in-degree centrality values, we see that, although each country has its own domestic debate about national (e.g., \#ukip \#bbcbias, \#whyivotedukip in the UK) as well as European issues, there is also transnational debate about the EP elections in which all countries engage in. This is evident from the most popular between-country hashtags depicted in Table 5. In all, while especially in the countries with many Twitter users there is a lot of conversation about Europe and the EP elections visibly taking place at the national level, there is clearly cross-country conversation about this topic too (although as evident from the most prominent within-country hashtag this conversation is far less voluminous). As an indication, the top 10 hashtags of the network are \#eu, \#telleurope, \#withjuncker, \#europe, \#ukraine, \#bringbackourgirls, \#ep, \#ttip and \#eurovision, all of whom are at the very centre of the network and receive edges from 24 countries. The very existence of transnational discussion, even if not very important, sends a hopeful message about the future shaping of a European public sphere.

\subsection{Hashtags associated with the Spitzenkandidaten}

In the 2014 European elections, the major political groups promoted lead candidates in an effort to promote visibility for the elections and mobilize turnout (Schmitt et al., 2015). An important aspect of public engagement with the lead candidates is social media discussion. We examined the prominence of the three most visible lead candidates - Jean-Claude Juncker, Martin Schulz, and Guy Verhofstadt — by selecting all tweets which contain the surnames of these three candidates 9

\footnotetext{
${ }^{9}$ Our search criteria based on the lead candidates' twitter user names meant that false-positive results tweets containing the candidate's surname string that did not actually refer to the lead candidate - were almost non-existent.
} 
The word cloud in Figure 7 shows the hashtags associated with mentions of the Lead Candidates. The colour and position of the hashtag indicates which candidate it co-occurred with most, and the size of the word is determined by the margin by which it is associated with that candidate more than the others. Hashtags specifically and explicitly voicing support for a particular candidate were successful in dominating the discussion associated with that candidate's name. 


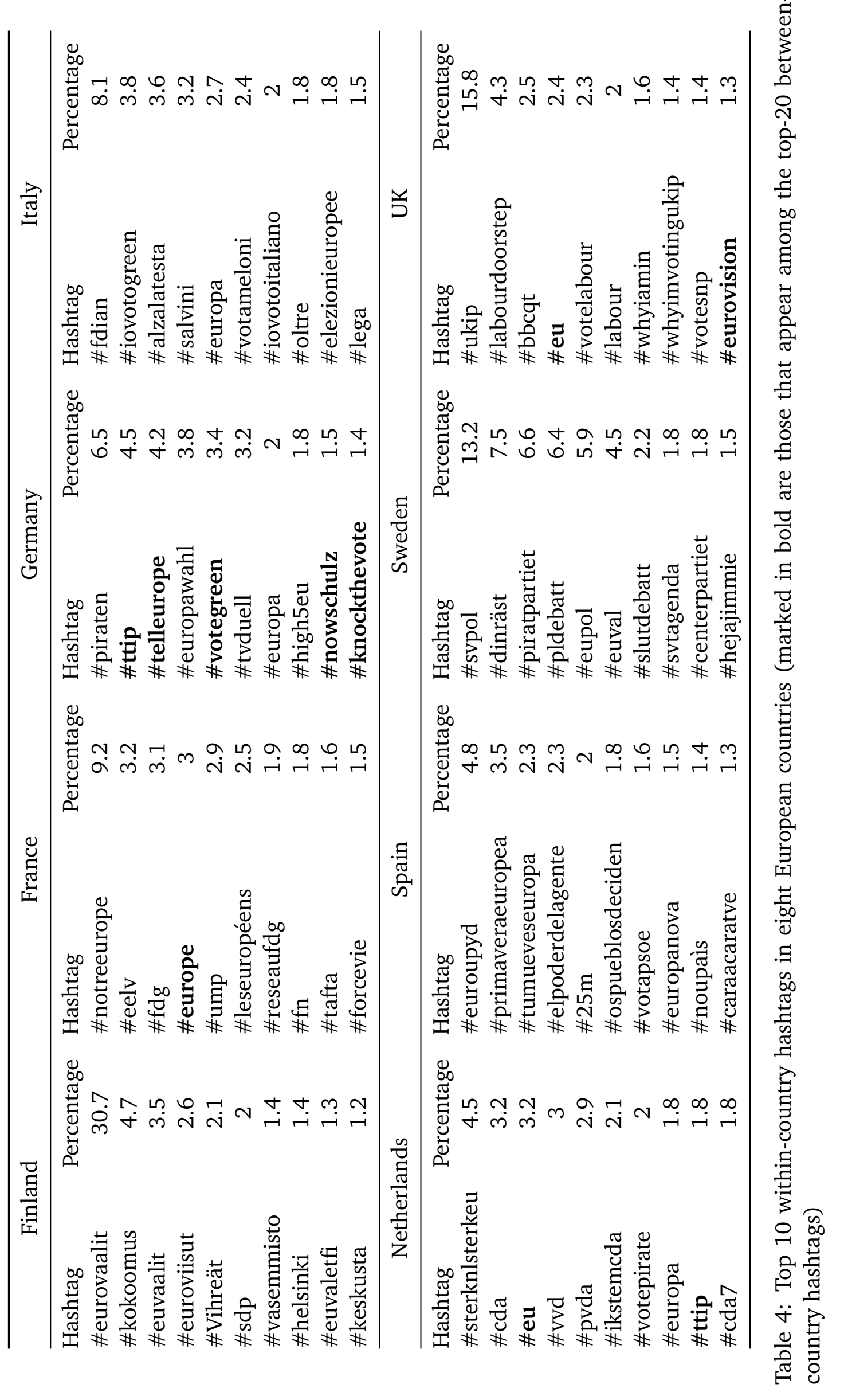


Figure 8 shows the relative prominence of mentions of the candidates names over the duration of the campaign. Among these three candidates, Martin Schulz was the most prominent in the early stages of the campaign. Over the days surrounding the leaders' debate on May 15th, Verhofstadt received a notable rise in support, which also coincided with media coverage of the launch of his campaign poster, mirrored in our data with the hashtag \#Verhofstadt poster. Schulz again dominated the discussion in the period leading to and during the election, but as the election results became clear from May 25, Juncker rose to prominence in the discussion. As the leader of the EPP, the party which had secured the most votes, he was identified in media reports as being most likely to become European Commission president.

\section{The Content of Social Media Communication}

Our examination of hashtags associated with patterns of social media communication have already hinted at the content of these communications. In this section we analyze the content more deeply, examining its relationship to emotional tone and by implication, Euroskepticism, and how it is used to convey messages about the candidates' preferences for EU versus left-right policy issues.

\subsection{Hashtags associated with positioning on the EU Dimension}

Many of the top within-national hashtags refer to national parties with Euroskeptic views. The network centrality measures suggest that Euroskeptic hashtags are not so prominent cross-nationally. In order to directly discover hashtags that represent a position on EU integration, we used an "elastic net" regularized regression model (Zou and Hastie, 2005) to measure the association between hashtag frequency and the EU integration policy of MEPs, using estimates of policy positions calculated from the Twitter follower graph and validated against EU positions from the expert judgements (Barberá, 2015; Barberá et al., 2015). The elastic net regression combines the penalties of LASSO and ridge regression, so that a limit is imposed on the sum of both the absolute and the squared values of the 


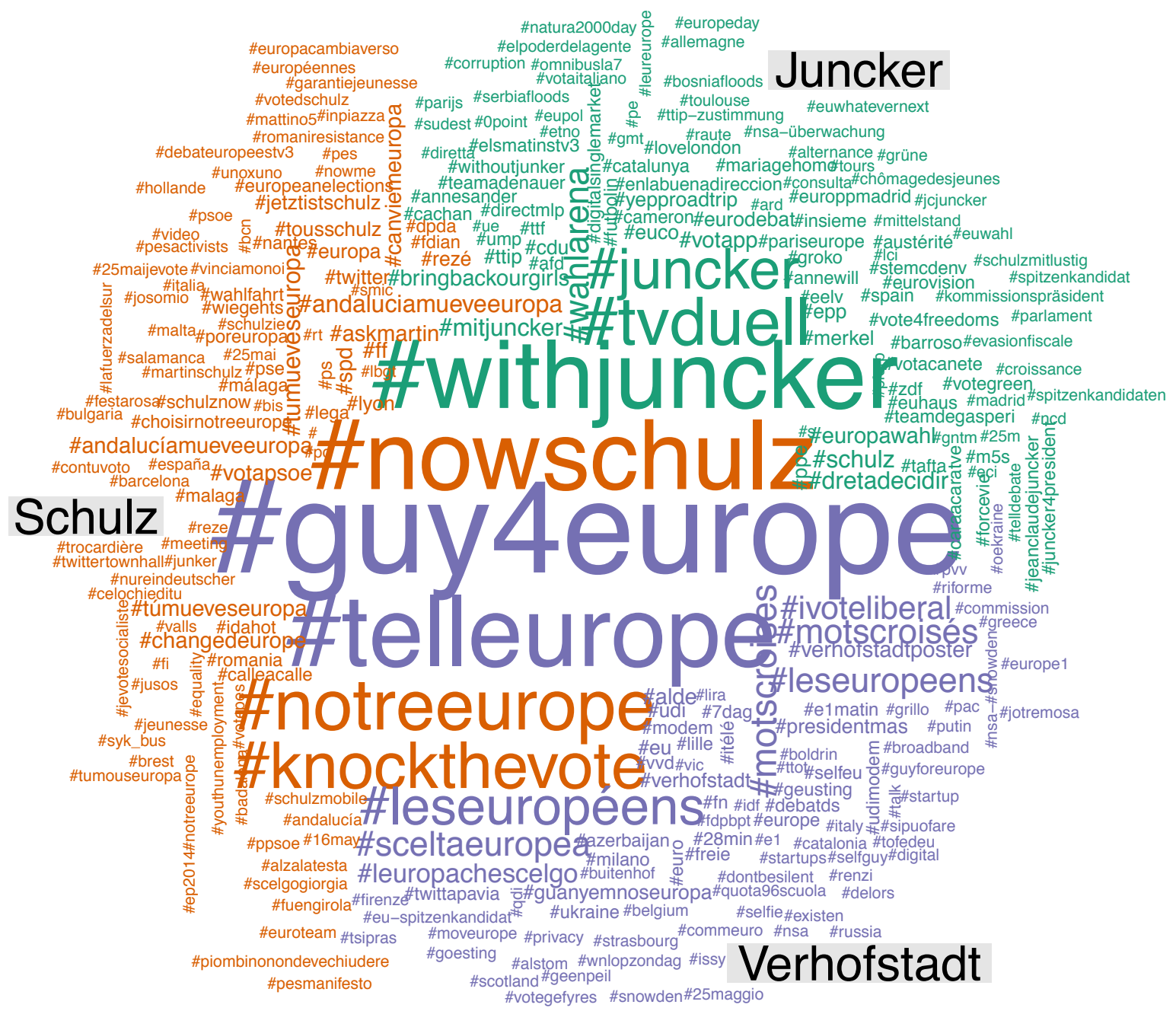

Figure 7: Hashtags co-occurring with names of Lead Candidates. Each hashtag is positioned and colored by the candidate with which it has the highest relative co-occurrence. 


\begin{tabular}{lr}
\hline Between-country hashtag & $\begin{array}{r}\text { In-degree } \\
\text { centrality value }\end{array}$ \\
\hline \#eu & 24 \\
\#telleurope & 24 \\
\#withjuncker & 24 \\
\#europe & 21 \\
\#ukraine & 21 \\
\#bringbackourgirls & 20 \\
\#ep & 20 \\
\#ttip & 19 \\
\#eurovision & 19 \\
\#europeday & 19 \\
\#ff & 18 \\
\#russia & 18 \\
\#euco & 18 \\
\#pforp & 18 \\
\#knockthevote & 17 \\
\#votegreen & 16 \\
\#nowschulz & 16 \\
\#selfie & 16 \\
\#ivoteliberal & 16 \\
\#lgbt & 16 \\
\hline
\end{tabular}

Table 5: Top 20 between-country hashtags

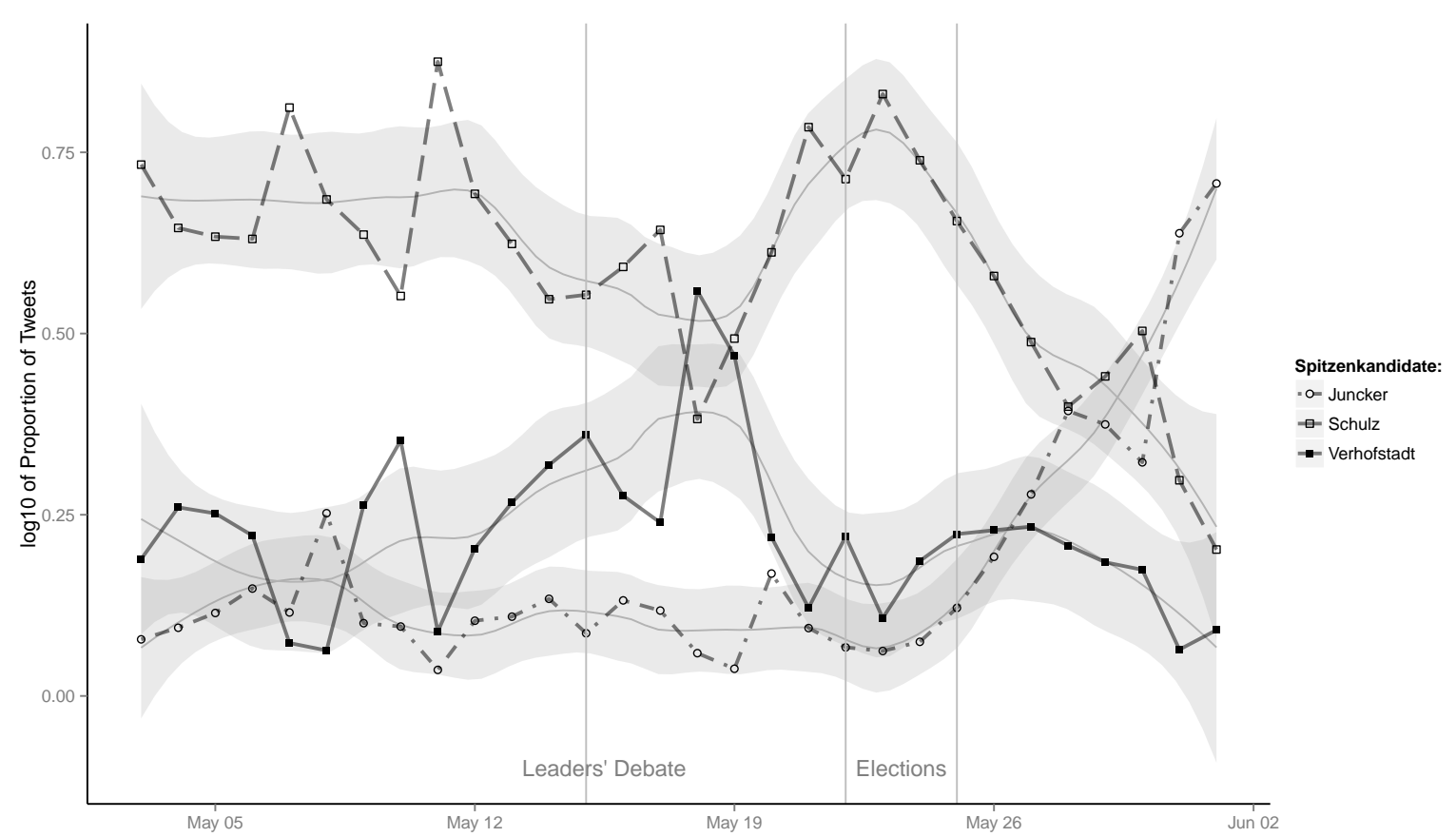

Figure 8: Proportional occurrence rates of Lead Candidate names and prominent hashtags over duration of campaign. 
coefficients (the L1 and L2 norms).

We extracted the frequency with which hashtags occurred in the tweets of each candidate, for hashtags that were used by at least ten candidates and occurred at least twenty times in total, and weighted the frequencies by the product of term frequency and inverse document frequency ( $t f-i d f)$, considering the tweets of each candidate as a single document. We excluded candidates that produced fewer than 200 characters of text in total. After applying these thresholds, 886 hashtags remained ${ }^{10}$

The wordclouds in figure 9 show the 70 most frequent hashtags that had non-zero coefficients in the resulting models, where positive coefficients were associated with a pro-EU integration position, and negative co-efficients with a Euroskeptic position. The position of a hashtag in the wordcloud indicates which stance it is more associated with, and the size of the word indicates the absolute value of the regression coefficient of the hashtag.

In the cross-national hashtags, mention of \#serbia is predictive of support for EU integration, perhaps reflecting an ongoing debate over Serbian accession to the EU in during 2014, as well as news coverage of EU aid provided to Serbia in response to severe floods on May 19th 2014. The hashtag \#Geithner is strongly associated with a negative position on EU integration - news archives from the campaign period show that a book published on 12th May 2014 by former US Treasury Secretary Timothy Geithner heavily criticised EU leaders' handling of the financial crisis. In some cases, the same issue is discussed by both sides of the policy debate, using different hashtags. For example, \#migration is associated with a pro-EU stance, and \#immigration with a Euroskeptic position.

\footnotetext{
${ }^{10}$ We fit the elastic net model using these hashtags as parameters, and the EU policy position of the candidate as the dependent variable. The model fit was evaluated using ten-fold cross-validation, using a mixing parameter of $\alpha=0.005$. The value for the $\lambda$ parameter, which determines the amount of shrinkage applied to the coefficients, was 2.34 , chosen to minimize the mean-squared error of prediction. For the best crossnational model, with 490 non-zero coefficients, the variation in EU policy position explained by the hashtags selected is $73 \%$. We also fit models with lower frequency thresholds for individual countries for which enough candidate tweet text was available. Perhaps due to a more homogeneous vocabulary, the fit of these models was better, with the UK, Spain, and Germany hashtags accounting for $83 \%, 91 \%$ and $76 \%$ of the deviance respectively.
} 


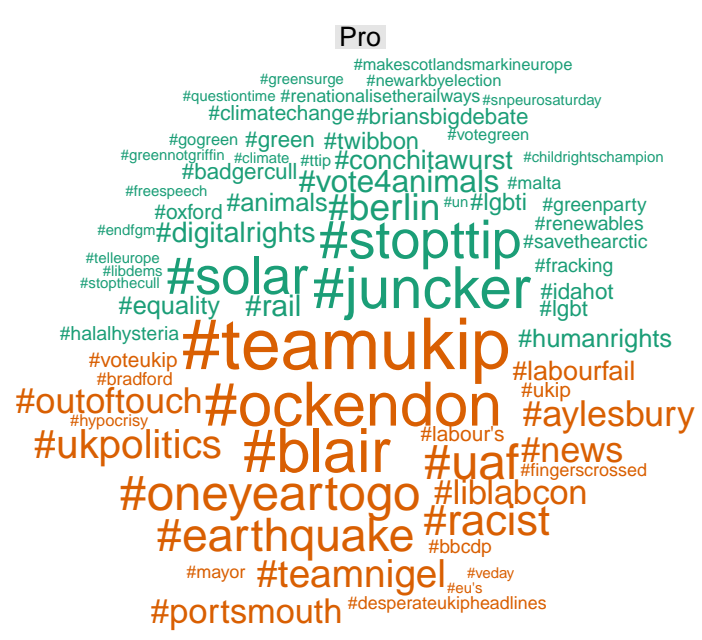

anti

\author{
Pro \\ \#mitiuncker \#ivoteliberal \#furdpop \\ \#wahlarena \#jetztistschulz \\ \#jugendarbeitslosigkeit \\ \#tvduell \# \# \\ \#gehwaehlen \#euco\#steinmeier \\ \#wahlkampf \#europawahl $\begin{aligned} & \text { \#tragudo } \\ & \text { \#totopes }\end{aligned}$ \\ \#theprogressives \#ddub\#europa \# \#euwahl

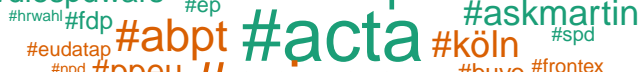 \\ 保pod \#ppeu \#privaCy \#monsanto \\ \#n

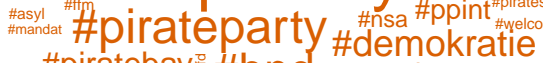 \\ \#piratebay \#bnd \#snowden \#googlenest \\ \#nrwat\#aachen\#eurovision \\ \#piratenpartei \#guerillastriseken \\ \#freepetersunde \#stopttip \\ \#kosningar \#sharingiscaring \\ anti
}

(b) Germany

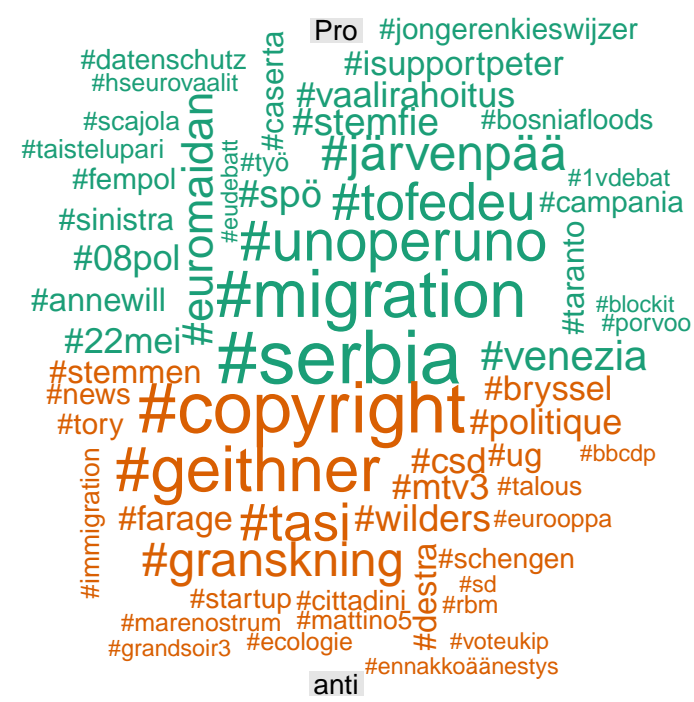

(c) Spain

(d) All countries

Figure 9: Hashtags associated with EU integration in the United Kingdom and Germany 


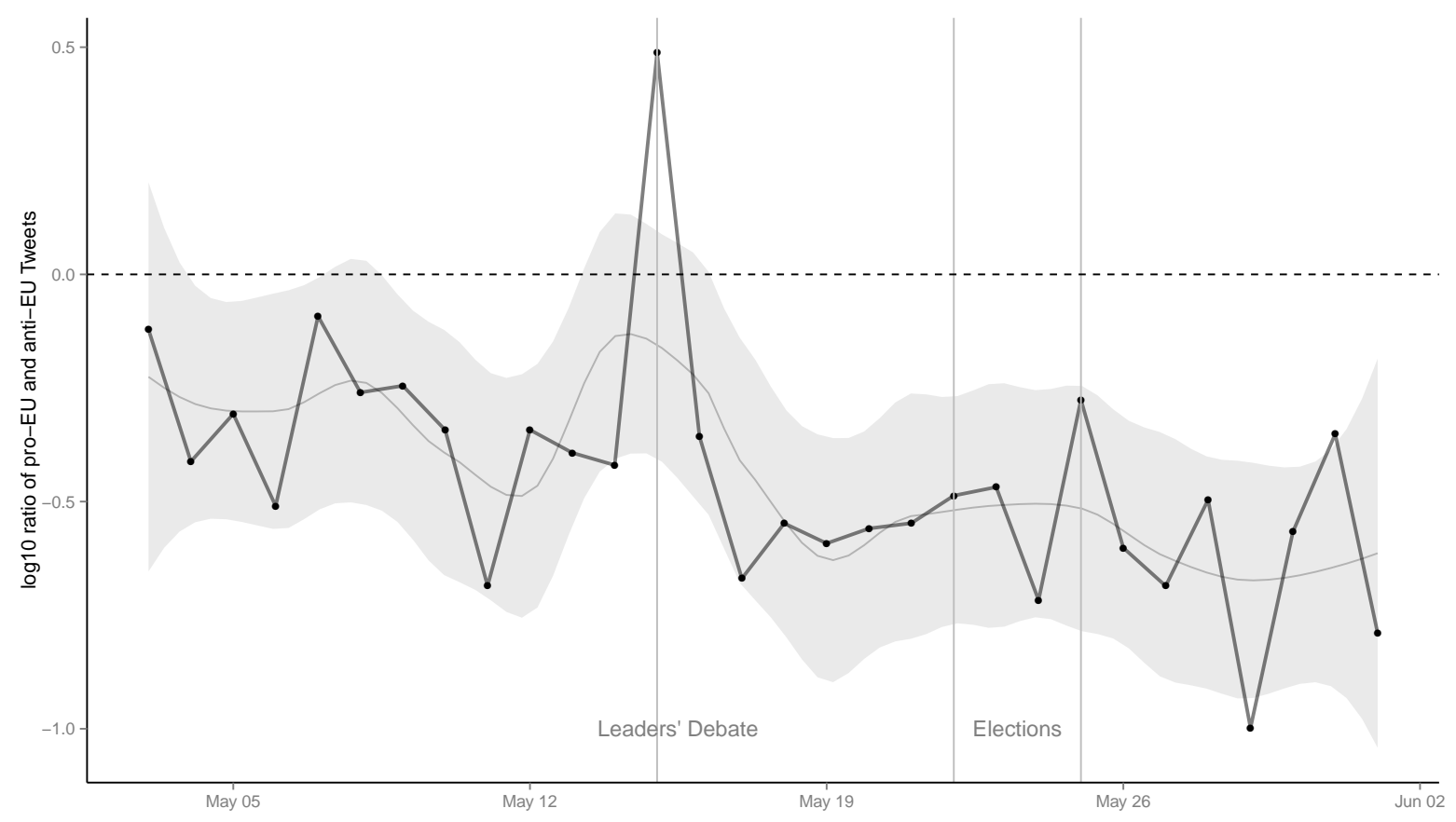

Figure 10: Log ratio of pro and anti- EU integration hashtags in tweets from non-candidates over the duration of the campaign.

\subsection{Positive versus negative sentiment}

Expert surveys allow us to link policy positions to candidate communications, but in order to gauge the content of those communications, we need text analytic tools. Here, we adopt the Linguistic Inquiry and Word Count (LIWC) (Pennebaker et al., 2007) psychological dictionary to analyze the emotional tone of tweets originating from candidates. The LIWC dictionary contain lists of words and word stems linked to a number of psychological categories developed and refined by Pennebaker et al. (2001), including positive or negative emotional tone. One of the most widely used language dictionaries in existence, the LIWC has been applied to investigate political intuitions and ideology (Graham et al., 2009) and in a variety of social science applications (O‘Connor et al., 2011).

The LIWC is particularly useful in our case as it provides equivalent versions for six major languages used in Europe: English, Spanish, German, Italian, French, and Dutch. Applying the dictionaries to the appropriate languages, we aggregated all tweets for each candidate, and scored their emotional tone as the log ratio of positive to negative emotion, determined by the sum of the counts of terms in the dictionary category. In Table 6, we 


\begin{tabular}{lr}
\hline \hline & \multicolumn{2}{c}{ Dependent variable: } \\
\cline { 2 - 2 } EU Position & $0.041^{* * *}$ \\
& $(0.011)$ \\
Left-right & 0.008 \\
& $(0.036)$ \\
Left-right ${ }^{2}$ & -0.001 \\
& $(0.004)$ \\
English & $0.328^{* * *}$ \\
& $(0.047)$ \\
French & $-0.188^{* * *}$ \\
& $(0.052)$ \\
German & $-0.099^{*}$ \\
& $(0.053)$ \\
Italian & $-1.082^{* * *}$ \\
& $(0.056)$ \\
Spanish & $-0.097^{*}$ \\
Constant & $(0.055)$ \\
& $0.385^{* * *}$ \\
Observations & $(0.070)$ \\
$\mathrm{R}^{2}$ & 4,269 \\
Adjusted $\mathrm{R}^{2}$ & 0.205 \\
Residual Std. Error & 0.203 \\
F Statistic & $137.144^{* * *}(\mathrm{df}=8 ; 4260)$ \\
\hline \hline Note: & $0.1{ }^{* *} \mathrm{p}<0.05 ;{ }^{* * *} \mathrm{p}<0.01$ \\
&
\end{tabular}

Table 6: OLS regression of log ratio of positive to negative emotion as measured by the LIWC on tweets aggregated by candidate, for English, Spanish, German, Italian, French, and Dutch. Policy data from Chapel Hill Survey.

regressed this score on the Chapel Hill policy measures of each candidate's party, as well as a fixed effect for each language. The results show that while the emotional tone was unrelated to left-right positioning, it was strongly and positively related to the strength of preference for pro-European policy stances. For each additional point on the anti- to proEU positioning scale of a candidate's party, the emotional tone increased by 0.04 . We plot this marginal effect in Figure 11, which shows the clear relationship of EU positioning on emotional tone: a change of 5 points on this scale (from 2 to 7 ) is associated with a nearly $50 \%$ increase in emotional tone. By contrast, there is no significant association between the left-right position and the tone, indicating that the content of social media as observed through Twitter is more related EU issue positioning than classic left-right national issues. 

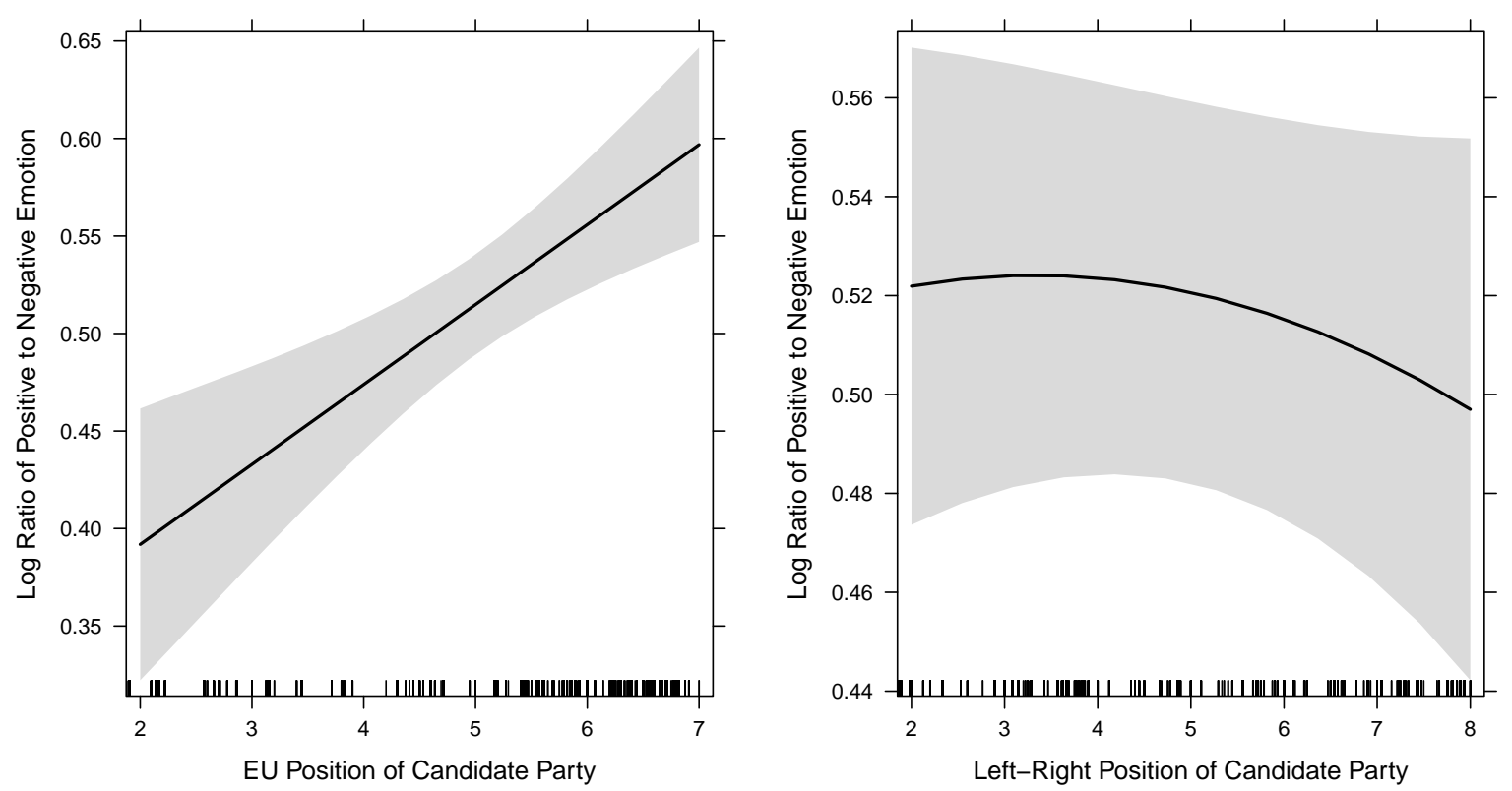

Figure 11: Marginal effects on emotional tone of EU and general left-right positions of the candidate's party. From Table 6 .

\section{Conclusions}

The 2014 EP elections represent one of the first instances in which the electoral competition across the entire 28 EU members states unfolded in a context in which new media technologies - especially social networking sites and micro-blogs - have become integral parts of electoral campaigning and providing avenues for communication between candidates and citizens. For the first time in the history of EP elections, party groups were able to nominate a candidate for the Presidency of the European Commission in a move that allowed them to run more focused and personalised electoral campaigns that would transcend national borders. Together with the eurozone crisis and the general rise of Euro-scepticism by the elections, the social media context in 2014 provided a fertile ground for exploring the use and content of political communications through social media, offering insights into the ongoing question as to whether European elections are primarily extensions of national political contests, or rather concern European-level issues.

We examined this question by investigating whether the adoption and usage of Twitter by politicians was linked to party policy positions. We also looked for evidence that would point to the existence of a European public sphere in which the discussion around 
EP elections transcends national borders. Finally, we examined the content of social media communications by candidates and followers to evaluate the overall tone of the campaign, and to see whether variations in this tone can be attributed more to preferences for and against the EU, versus classic left-right national divisions.

We found that the adoption and use of Twitter by politicians is mostly related to their position on the anti-pro EU dimension of political competition. While anti-EU party candidates were less likely to have Twitter accounts, the anti-EU party candidates who did have such accounts used them disproportionately relative to more mainstream candidates. They were much more active on Twitter than the mainstream pro-EU candidates, suggesting that they were using the platform to politicise further the EU dimension by promoting an anti-EU rhetoric as they have in other communication channels (de Vries and Hobolt, 2012; Hobolt and de Vries, 2015). Furthermore, we found a spike in campaign-related communications around the leaders' debate, the only event event outside of the voting itself that targeted a truly Europe-wide audience. Communication patterns, however, do not confirm our expectations about the establishment of a common EU public sphere on Twitter as, despite signs of a transnationalization of the debate about the EU, parallel discussions about EU topics unfolding within countries (using local hashtags) are dominant. Content analysis of the communications also shows us that, among candidates, hashtags associated with anti-EU stances are at least on par with hashtags reflecting pro-EU stances during the electoral campaign. Among the public, the anti-EU hashtags do a better job in capturing the attention of the citizens as they are used more often, although the balance was more even among candidate content. In explaining the emotional tone of this content in candidate communications, negativity was strongly associated with anti-EU policy preferences instead of left-right positioning. Together, these results demonstrate that political communication through social media reflects a discourse about European issues and policitizing the debate over the future and shape of EU institutions and policies, rather than providing an extension of political competition over traditionally national issues. 


\section{References}

Bakker, R., de Vries, C., Edwards, E., Hooghe, L., Jolly, S., Marks, G., Polk, J., Rovny, J., Steenbergen, M., and Vachudova, M. a. (2012). Measuring party positions in Europe: The Chapel Hill expert survey trend file, 1999-2010. Party Politics, 21(1):143-152.

Barberá, P. (2015). Birds of the same feather tweet together: Bayesian ideal point estimation using twitter data. Political Analysis, 23(1):76-91.

Barberá, P., Popa, S. A., and Schmitt, H. (2015). Prospects of Ideological Realignment(s) in the 2014 EP elections? Analyzing the Common Multidimensional Political Space for Voters, Parties, and Legislators in Europe. Presented at the 2015 Annual Meeting of the Midwest Political Science Association, April 16-19, Chicago.

Benoit, K. and Laver, M. (2012). The dimensionality of political space: Epistemological and methodological considerations. European Union Politics, 13:194-218.

Bode, L. and Dalrymple, K. E. (2014). Politics in 140 Characters or Less: Campaign Communication, Network Interaction, and Political Participation on Twitter. Journal of Political Marketing, (January 2015):141217143151003.

Castells, M. (2009). Communication power. Oxford University Press, New York.

Chadwick, A. (2014). The Hybrid Media System: Politics and Power. Oxford University Press, New York.

Crampton, J. W., Graham, M., Poorthuis, A., Shelton, T., Stephens, M., Wilson, M. W., and Zook, M. (2013). Beyond the geotag: situating 'big data' and leveraging the potential of the geoweb. Cartography and geographic information science, 40(2):130-139.

Dalton, R. and Welzel, C. (2014). The Civic Culture Transformed: From Alegiant to Assertive Citizens. Cambridge University Press, New York.

de Vries, C. and Hobolt, S. B. (2012). When dimensions collide: The electoral success of issue entrepreneurs. European Union Politics, 13(2):246-268.

De Vries, C. E. and Edwards, E. E. (2009). Taking Europe To Its Extremes: Extremist Parties and Public Euroscepticism. Party Politics, 15(1):5-28.

Evans, H., Cordova, V., and Sipole, S. (2014). Twitter Style: An Analysis of How House Candidates Used Twitter in Their 2012 Campaigns. PS: Political Science \& Politics, 47(2):454462 .

Gabel, M. and Hix, S. (2002). Defining the Eu Political Space: An Empirical Study of the European Elections Manifestos, 1979-1999. Comparative Political Studies, 35(8):934964.

Gibson, R. (2013). Party Change, Social Media and the Rise of 'Citizen-initiated' Campaigning. Party Politics.

Graham, J., Haidt, J., and Nosek, B. A. (2009). Liberals and conservatives rely on different sets of moral foundations. Journal of personality and social psychology, 96(5):1029. 
Grant, W. J., Moon, B., and Grant, J. (2010). Digital Dialogue? Australian Politicians' use of the Social Network Tool Twitter. Australian Journal of Political Science, 45(4):579-604.

Hansen, K. and Kosiara-Pederson, K. (2014). Cybercampaigning at the 2011 Danish General Election: How Candidates and Voters Make Use of Cyber-campaigning tools and the Electoral Effects of This. Journal of Information Technology \& Politics, 11(2):2016-219.

Hecht, B. and Stephens, M. (2014). A tale of cities: Urban biases in volunteered geographic information. Proc. of ICWSM.

Hix, S. and Marsh, M. (2007). Punishment or Protest? Understanding European Parliament Elections. The Journal of Politics, 69(2):495-510.

Hobolt, S. B. (2014). A vote for the President? The role of Spitzenkandidaten in the 2014 European Parliament elections. Journal of European Public Policy, 21(10):1528-1540.

Hobolt, S. B. and de Vries, C. E. (2015). Issue Entrepreneurship and Multiparty Competition. Comparative Political Studies, pages 0010414015575030-.

Hobolt, S. B. and Wittrock, J. (2011). The second-order election model revisited: An experimental test of vote choices in European Parliament elections. Electoral Studies, 30(1):2940.

Hooghe, L. and Marks, G. (2009). A Postfunctionalist Theory of European Integration: From Permissive Consensus to Constraining Dissensus. British Journal of Political Science, 39(01):1-23.

Hooghe, L., Marks, G., and Wilson, C. J. (2002). Does Left/Right Structure Party Positions on European Integration? Comparative Political Studies, 35:965-989.

Jungherr, A. (2014a). The Role of the Internet in Political Campaigns in Germany. German Politics.

Jungherr, A. (2014b). Twitter in Politics: A Comprehensive Literature Review. SSRN.

Jungherr, A. and Jürgens, P. (2014). Through a Glass, Darkly: Tactical Support and Symbolic Association in Twitter Messages Commenting on Stuttgart 21. Social Science Computer Review, 32(1):74-89.

Koopmans, R. and Statham, P. (2010). The making of a European public sphere: Media discourse and political contention. Cambridge University Press, Cambridge.

Kriesi, H. and Grande, E. (2014). Political debate in a polarizing Union. In Cramme, O. and Hobolt, S. B., editors, Democratic Politics in a European Union under Stress. Oxford University Press, Oxford.

Larsson, A. (2015). The EU Parliament on Twitter - Assessing the Permanent Online Practices of Parliamentarians. Journal of Information Technology \& Politics, 12(2):149-166.

Lees-Marshment, J. (2001). Political Marketing and British Political Parties: The Party's Just Begun. Manchester University Press, Manchester. 
Lilleker, D., Koc-Michalska, K., Schweitzer, E., Jacunski, M., Jackson, N., and Vedel, T. (2011). Informing, engaging, mobilizing or interacting: Searching for a European model of web campaigning. European Journal of Communication, 26(3):195-213.

Lorenzo-Rodríguez, J. and Madariaga, A. G. (2015). Going public with a private profile? analyzing the online strategies of 2014 european parliament election candidates. Presented at the 2015 Annual Meeting of the Midwest Political Science Association, April 16-19, Chicago.

McElroy, G. and Benoit, K. (2007). Party Groups and Policy Positions in the European Parliament. Party Politics, 13(1):5-28.

O‘Connor, B., Bamman, D., and Smith, N. A. (2011). Computational text analysis for social science: Model assumptions and complexity. public health, 41(42):43.

Pennebaker, J. W., Booth, R. J., and Francis, M. E. (2007). Linguistic Inquiry and Word Count: LIWC2007. University of Texas at Austin and University of Auckland, New Zealand.

Pennebaker, J. W., Francis, M. E., and Booth, R. J. (2001). Linguistic inquiry and word count: Liwc 2001. Mahway: Lawrence Erlbaum Associates, 71:2001.

Popa, S. A. and Dumitrescu, D. (2015). National but European? Visual manifestations of Europe in national partiesâĂŹ Euromanifestos since 1979. Party Politics.

Reif, K. and Schmitt, H. (1980). Nine Second-Order National Elections: A Conceptual Framework for the Analysis of European Election Results. European Journal of Political Research, 8(1):3-44.

Rohrschneider, R., Schmitt, H., and Sebastian, P. (2015). Polarizing Without Politicizing: The Effect of Lead CandidatesâĂŹ Campaigns on Perceptions of the EU Democracy. Presented at the 2015 Annual Meeting of the Midwest Political Science Association, April 16-19, Chicago.

Rovny, J. (2012). Who emphasizes and who blurs? Party strategies in multidimensional competition. European Union Politics, 13(2):269-292.

Schmitt, H. (2005). The European Parliament Elections of June 2004: Still Second-Order? West European Politics, 28(3):650-679.

Schmitt, H., Hobolt, S. B., and Popa, S. A. (2015). Does personalization increase turnout? Spitzenkandidaten in the 2014 European Parliament elections. European Union Politics, 16(3):347-368.

Strandberg, K. (2013). A social media revolution or just a case of history repeating itself? The use of social media in the 2011 Finnish parliamentary elections. New Media \& Society, pages 1461444812470612-.

Theocharis, Y., Barberá, P., Fazekas, Z., and Popa, S. (2015). A Bad Workman Blames His Tweets? The Consequences of Citizens Uncivil Twitter Use when Interacting with Party Candidates. 2015 Annual Meeting of the American Political Science Association.

van der Eijk, C. and Franklin, M. (1996). Choosing Europe? The European Electorate and National Politics in the face of Union. University of Michigan Press, Ann Arbor. 
van der Eijk, C. and Franklin, M. (2004). Potential for contestation on European matters at national elections in Europe. In Marks, G. and Steenbergen, M. R., editors, European Integration and Political Conflict, pages 32-50. Cambridge University Press, Cambridge, MA.

Vergeer, M., Hermans, L., and Cunha, C. (2012). Web campaigning in the 2009 European Parliament elections: A cross-national comparative analysis. New Media \& Society, 1(15):128-148.

Vergeer, M., Hermans, L., and Sams, S. (2011). Online social networks and micro-blogging in political campaigning: The exploration of a new campaign tool and a new campaign style. Party Politics, 19(3):477-501.

Zou, H. and Hastie, T. (2005). Regularization and variable selection via the elastic net. Journal of the Royal Statistical Society: Series B (Statistical Methodology), 67(2):301-320. 